\title{
Standardized Methods for Grand Canyon Fisheries Research 2015
}

Chapter 12 of

Section A, Biological Science

Book 2, Collection of Environmental Data

Techniques and Methods 2=A12

U.S. Department of the Interior

U.S. Geological Survey 
FRONT COVER

A humpback chub (Gila cypha) in the Colorado River. Photo by Randall Babb, Arizona Game and Fish Department. 


\section{Standardized Methods for Grand Canyon Fisheries Research 2015}

By William R. Persons, David L. Ward, and Luke A. Avery

Chapter 12 of

Section A, Biological Science

Book 2, Collection of Environmental Data

Techniques and Methods 2-A12 


\title{
U.S. Department of the Interior \\ SALLY JEWELL, Secretary
}

\section{U.S. Geological Survey Suzette M. Kimball, Acting Director}

\author{
U.S. Geological Survey, Reston, Virginia/ \\ First Release: 2013 \\ Revised: January 2015 (ver. 1.1)
}

For product and ordering information: World Wide Web: http://www.usgs.gov/pubprod
Telephone: 1-888-ASK-USGS

For more information on the USGS - the Federal source for science about the Earth, its natural and living resources, natural hazards, and the environment: World Wide Web: http://www.usgs.gov

Telephone: 1-888-ASK-USGS

Any use of trade, firm, or product names is for descriptive purposes only and does not imply endorsement by the

U.S. Government.

Although this report is in the public domain, permission must be secured from the individual copyright owners to reproduce any copyrighted material contained within this report. 


\section{Contents}

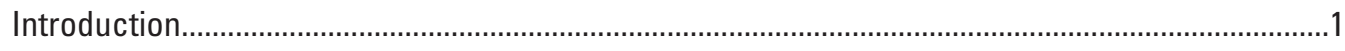

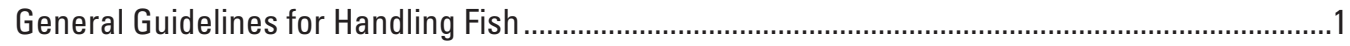

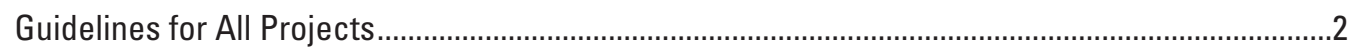

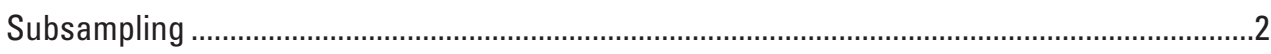

Rare-Nonnative-Fish Preservation ...............................................................................

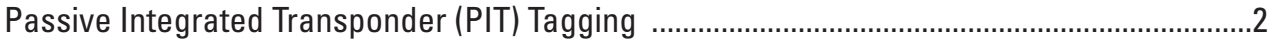

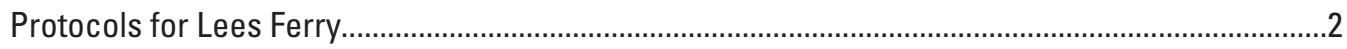

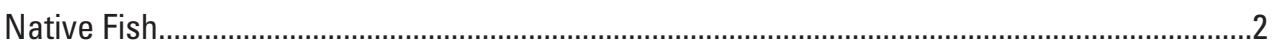

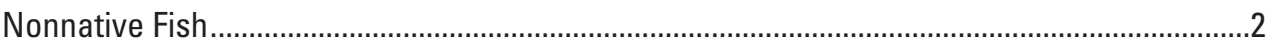

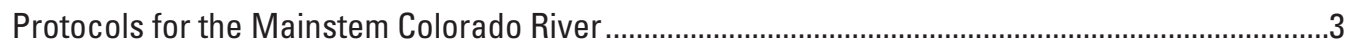

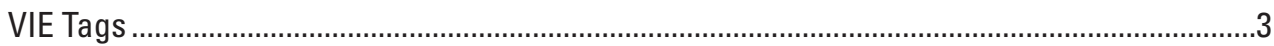

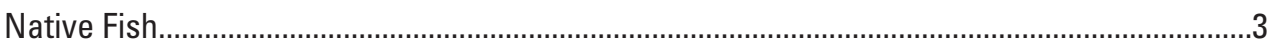

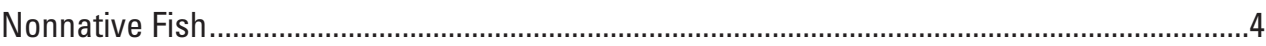

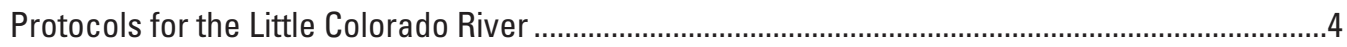

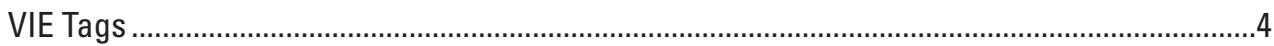

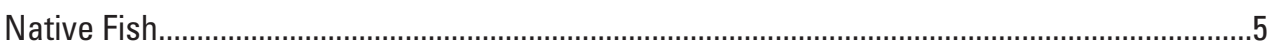

Special Conditions for Tagging Bluehead Suckers .........................................................

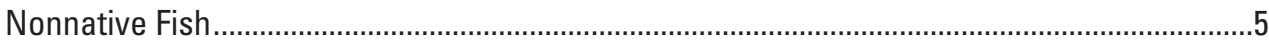

Protocols Common to All Projects .......................................................................................

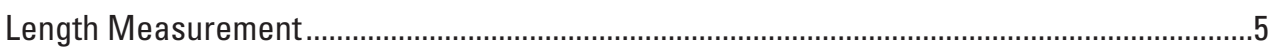

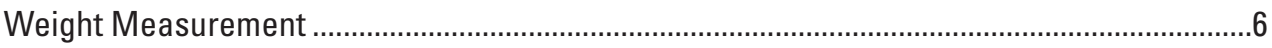

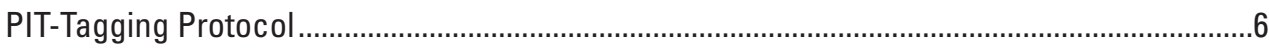

Tips for Fish that May Have Multiple PIT Tags..............................................................

Best Practices for Keeping PIT Tags and Needles Sterile .............................................6

PIT-Tagging Humpback Chub.....................................................................................

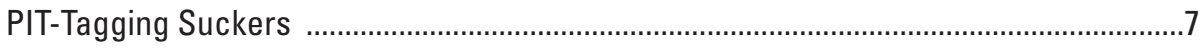

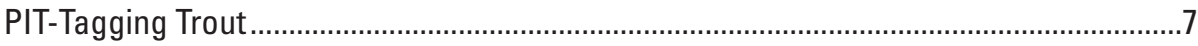

PIT-Tagging Catfish and Carp (Dorsal Musculature) ..........................................................

Verifying PIT Tags ...............................................................................................................

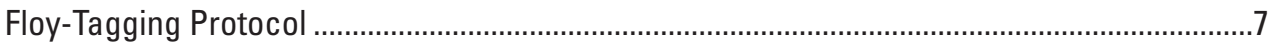

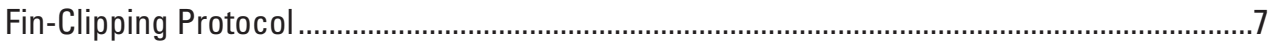

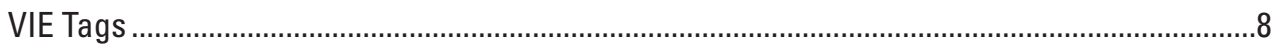

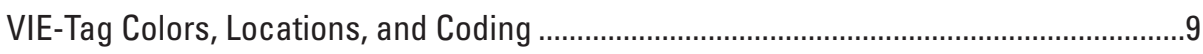

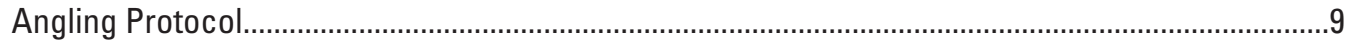

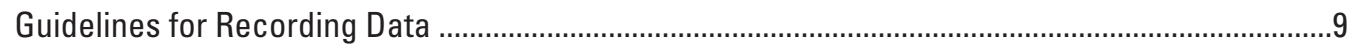

Standard Data Label for Preserving Specimens ...................................................................

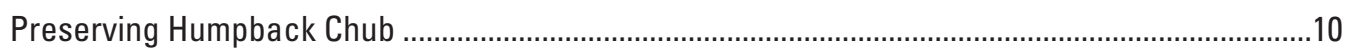

Bite Mark Documentation ........................................................................................................

Parasite/Disease Documentation .................................................................................................

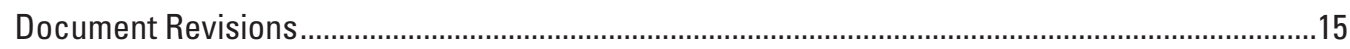

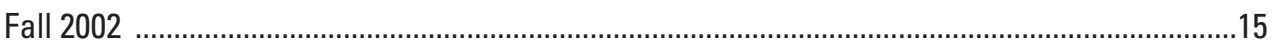

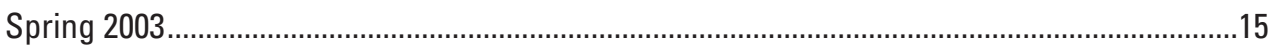

September 2003 


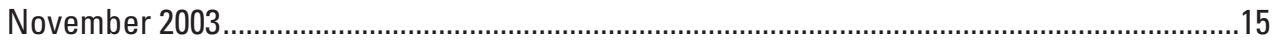

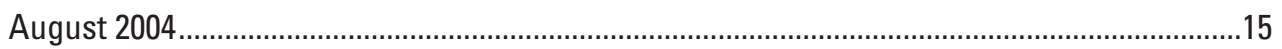

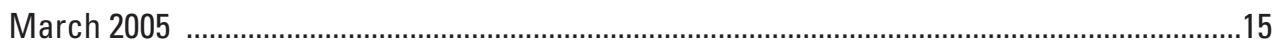

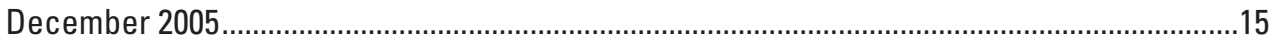

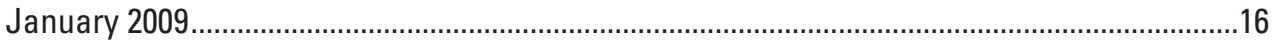

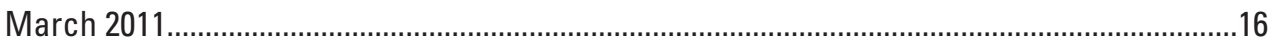

March 2012

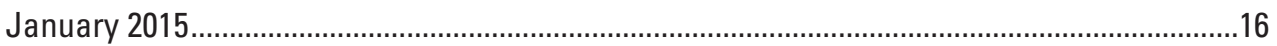

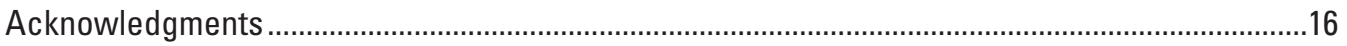

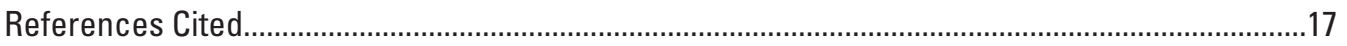

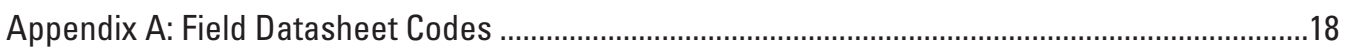

\section{Figures}

1. Illustration showing an example of fork-length and total-length measurements .....................

2. Photograph showing a PIT-tag insertion point in a Humpback chub........................................

3. Photograph showing a PIT-tag insertion point in a sucker. .....................................................

4. Photograph showing a PIT-tag insertion point in a rainbow trout. .........................................

5. Photograph showing a PIT-tag insertion point in a channel catfish...........................................5

6. Photograph showing a PIT-tag insertion point in a common carp..........................................5

7. Example of horizontal lines over letters when recording PIT-tag numbers on a datasheet ...7

8. Diagram showing Floy-tag insertion point at base of dorsal fin between pterygiophores......7

9. Drawing showing fins and their corresponding codes on left side humpback chub ...............8

10. Photographs showing the proper adipose-fin clip on trout and catfish ..................................8

11. Line drawing showing possible location codes for visible implant elastomer tag ..................8

12. Picture of Carolina rig used for standardized angling sampling ..........................................

13. Example of properly completed sample data label ...............................................................

14. Flow chart showing native fish handling and tagging guidelines at Lees Ferry.....................10

15. Flow chart showing nonnative fish handling and tagging guidelines at Lees Ferry ...............11

16. Flow chart showing native fish handling and tagging guidelines in mainstem Colorado River downstream of Lees Ferry ...................................................12

17. Flow chart showing nonnative fish handling and tagging guidelines in mainstem Colorado River downstream of Lees Ferry .................................................13

18. Flow chart showing native fish handling and tagging guidelines in the Little Colorado River ......................................................13

19. Flow chart showing nonnative fish handling and tagging guidelines in the Little Colorado River ............................................................................................14

20. Flow chart showing decision tree for PIT tagging fish which may have multiple tags..........14

Conversion Factors

\begin{tabular}{|c|c|c|}
\hline Multiply & By & To obtain \\
\hline \multicolumn{3}{|c|}{ Length } \\
\hline inch (in.) & 2.54 & centimeter $(\mathrm{cm})$ \\
\hline inch (in.) & 25.4 & millimeter $(\mathrm{mm})$ \\
\hline mile (mi) & 1.609 & kilometer (km) \\
\hline
\end{tabular}




\title{
Standardized Methods for Grand Canyon Fisheries Research 2015
}

\author{
By William R. Persons, David L. Ward, and Luke A. Avery
}

\section{Introduction}

This document presents protocols and guidelines to persons sampling fishes in the Grand Canyon, to help ensure consistency in fish handling, fish tagging, and data collection among different projects and organizations. Most such research and monitoring projects are conducted under the general umbrella of the Glen Canyon Dam Adaptive Management Program and include studies by the U.S. Geological Survey (USGS), U.S. Fish and Wildlife Service (FWS), National Park Service (NPS), the Arizona Game and Fish Department (AGFD), various universities, and private contractors. This document is intended to provide guidance to fieldworkers regarding protocols that may vary from year to year depending on specific projects and objectives. We also provide herein documentation of standard methods used in the Grand Canyon that can be cited in scientific publications, as well as a summary of changes in protocols since the document was first created in 2002.

\section{General Guidelines for Handling Fish}

Respectful and careful treatment of fish is critical to the long-term success of monitoring and research programs. Traumatized fish can exhibit abnormal physiologic, behavioral, and ecologic responses that challenge study purposes (Nickum, 1988). Rough or improper handling of fish is a source of stress that can lead to disease or death. Delayed mortality as a result of improper handling may not be immediately apparent to researchers but can occur hours to days later (Stickney, 1983), causing misleading study results and poor public opinion and potentially resulting in the loss of permits and cancellation of projects. Researchers should be sensitive to public perception and prepared to explain sampling activities. All field personnel should be familiar with and strictly adhere to research permit guidelines and limitations. Sampling procedures should leave sites as undisturbed as possible, and capture techniques should minimize injury to fish.
Although specific fish-handling procedures may vary from one project to another, all sampling should incorporate the following general guidelines:

- Be respectful of all fish, regardless of size and species.

- Minimize the time that fish are out of the water.

- Change water frequently when fish must be held for more than a few minutes or if you see fish surfacing for air. Remember that handling stress increases as water temperature increases. Utilize aerators if available.

- Do not put more than 8 to 10 large fish in your workup bucket at one time; leave the rest in a net in the river to minimize stress.

- Be aware that watch straps, lapel badges, and jewelry can damage fish.

- Do not hold fish tightly around the throat, and avoid touching the gills.

- Rinse all sunscreen or lotions from hands prior to handling fish.

- Always wet hands and equipment such as nets and fish boards before use. Dry hands and equipment cause damage to fish skin by removing coatings that protect fish from disease. Equipment such as length boards and scales become hot in the sun and can damage fish if not wetted before use.

- Shake hoop nets when removing them from the water. Check carefully for small fish that may have become lodged between net folds. Fish mistakenly left in nets are a large and avoidable source of researcher-caused mortality.

- Document accidentally killed native species on datasheets and preserve the specimen with an accompanying standard label.

Specific procedures for handling fish vary by location and project. General descriptions follow for fish handling procedures for Lees Ferry, the mainstem Colorado River, and the Little Colorado River. 


\section{Guidelines for All Projects}

\section{Subsampling}

For abundant small-bodied fishes, for example, speckled dace (Rhinichthys osculus), take a subsample (30-50 individuals of each species), record total length (TL) to the nearest millimeter and sexual characteristics, examine all fish > 40 millimeters (mm) for visible implant elastomer (VIE) tags, and then count the remaining, nonsubsampled fish. Attempt to randomize your selection process, or else you will bias your length data because of your bucket sampling method. Be especially careful to avoid selecting for larger specimens.

Current subsampling procedure for rainbow trout is to measure the fork length (FL) of the first 50 fish $<150 \mathrm{~mm} \mathrm{FL}$ and check the rest for passive integrated transponder (PIT) tags.

\section{Rare-Nonnative-Fish Preservation}

If you are trained to do so, take otoliths from rare nonnative fish (for example, smallmouth bass [Micropterus dolomieu], walleye [Sander vitreus], green sunfish [Lepomis cyanellus]) or preserve the head of the fish for later otolith removal in the lab. If a rare fish is sampled, record TL to the nearest millimeter, weight to the nearest gram (when possible), location, date, gear, and disposition ( $\mathrm{DP}=$ dead preserved); add a note in the comments on the datasheet and label the sample. If the fish is small, cut open its stomach cavity and preserve the fish with ethanol in a labeled jar. If the fish is too big to preserve, preserve its head in ethanol and check stomach contents (in the field). Record stomach contents on the basis of visual observation of large, identifiable items; also record in the comments field on the datasheet whether stomach contents and head were sampled. Back in the laboratory, represerve the specimen with fresh ethanol and send to David Ward, USGS Grand Canyon Monitoring and Research Center, 2255 N. Gemini Drive, Flagstaff, AZ 86001, telephone (928) 556-7280.

\section{Passive Integrated Transponder (PIT) Tagging}

Become familiar with PIT-tag-reader operation and be sure readers are configured to scan and store tags. All native fish $>300 \mathrm{~mm}$ TL should be scanned for the presence of a PIT tag using a 134.2-kiloHertz $(\mathrm{kHz})$ reader (either a Biomark FS2001, commonly called a cheeseblock, or a Biomark 601, commonly called a shoe horn) and a $400-\mathrm{kHz}$ reader (old Destron-Fearing blue reader) or a Biomark Pocket EX reader. Native fish with only a $400-\mathrm{kHz}$ tag should also receive a $134.2-\mathrm{kHz}$ tag, and both numbers should be recorded (134.2-kHz tags in PITTAG_1 field and 400-kHz tags in PITTAG_2 field). See "PIT-Tagging Protocol" section for tips on scanning fish.

\section{Protocols for Lees Ferry}

The following protocols apply primarily to long-term monitoring in the Lees Ferry tailwater reach. The area has been sampled by several projects, primarily the Lees Ferry long-term monitoring project (Makinster and others, 2011) and the Rainbow Trout Early Life Stages study (Korman and Campana, 2009; Korman and Melis, 2011), and more recently the Natal Origins project (Project BIO 2.E18, Glen Canyon Dam Adaptive Management Program Biennial Budget and Work Plan-Fiscal Years 2011-2012).

\section{Native Fish}

Guidelines for handling and tagging native fish at Lees Ferry are summarized below and on page 10. Measure TL and FL of native fish to the nearest millimeter and examine each fish for external parasites, diseases (see "Parasite/Disease Documentation" section), and sexual characteristics. Humpback chub (Gila cypha) $>80 \mathrm{~mm}$ TL should be scanned for the presence of a PIT tag, and any humpback chub $>80 \mathrm{~mm}$ TL without a $134.2-\mathrm{kHz}$ tag should be tagged with one. All other native fish $>149 \mathrm{~mm}$ TL should be scanned for the presence of a PIT tag, and fish without a 134.2-kHz tag should receive one.

\section{Nonnative Fish}

Guidelines for handling and tagging nonnative fish at Lees Ferry are summarized in figure 15. Measure FL of rainbow trout (Oncorhynchus mykiss) and TL of all other fish to the nearest millimeter. Weigh each fish to the nearest gram and examine all:

- salmonids for the presence of an adipose- or pelvic-fin clip

- catfish (that is, channel catfish, Ictalurus punctatus, and black bullhead, Ameiurus melas) for the presence of an adipose-fin clip

- common carp (Cyprinus carpio) for the presence of a dorsal-spine or operculum clip

Standard protocol is to weigh all fish $>150 \mathrm{~mm}$ TL, except in inclement weather. All salmonids, catfish, and carp with a fin clip, and all rainbow trout 80 to $250 \mathrm{~mm} \mathrm{FL}$, should be checked for the presence of a PIT tag or Floy tag. If large numbers of small rainbow trout are collected, batches of fish can be scanned by moving a tag-reader wand in the bucket holding fish. The Natal Origins project, which was started in 2011, is PIT-tagging tens of thousands of juvenile rainbow trout. All brown trout (Salmo trutta) $>149 \mathrm{~mm}$ TL and all catfish $>99 \mathrm{~mm}$ TL without a PIT tag should be tagged and receive an adipose-fin clip. Carp $>99 \mathrm{~mm}$ TL without a PIT tag should be tagged and receive a dorsal spine clip. In previous years, all rainbow trout $>199 \mathrm{~mm}$ TL caught at random sites received a yellow AGFD code Floy tag; this practice is being discontinued in 2012. All fish except rare nonnatives should be released alive. 


\section{Protocols for the Mainstem Colorado River}

The following protocols apply to the mainstem Colorado River and its tributaries (except the Little Colorado River) downstream from Lees Ferry (also see pages 11-12). In 2012, projects in the area include AGFD mainstem monitoring (Makinster and others, 2010), the Natal Origins project, the FWS mainstem humpback chub aggregation-sampling trip, and any other trips that may be launched to sample fish. Nonnativespecies-removal efforts may be conducted in the Paria-toBadger Rapid reach of Marble Canyon, for which alternative nonnative-fish-handling procedures will apply (Bureau of Reclamation, 2011). Additional projects in tributaries which are subject to their own protocols include the NPS humpback-chub translocations in Havasu and Shinumo Creeks and the fish weir in Bright Angel Creek. PIT-tag information from these projects will be shared between Grand Canyon National Park and the Grand Canyon Monitoring and Research Center.

\section{Visible Implant Elastomer (VIE) Tags}

Fish $<150 \mathrm{~mm}$ TL (suckers $<200 \mathrm{~mm}$ ) should be checked carefully for VIE tags. Record recapture information, color and location of any VIE tags in the appropriate datasheet fields. See subsection below entitled "VIE Tag Colors, Locations, and Coding."

\section{Native Fish}

Measure TL and FL of native fish to the nearest millimeter (fig. 1) and examine each fish for external parasites, diseases (see "Parasite/Disease Documentation" section), and sexual characteristics. Examine bluehead suckers $>149 \mathrm{~mm}$ TL for a left-pelvic clip (LP2) and record whether one is present. Humpback chub $>80 \mathrm{~mm}$ TL should be scanned for the presence of a PIT tag, and any humpback chub $>80 \mathrm{~mm}$ TL without a PIT tag should receive one (fig. 2). All other native fish $>149 \mathrm{~mm}$ TL should be scanned for the presence

Figure 1. Illustration showing an example of fork-length and total-length measurements (adapted from Anderson and Neumann, 1996).

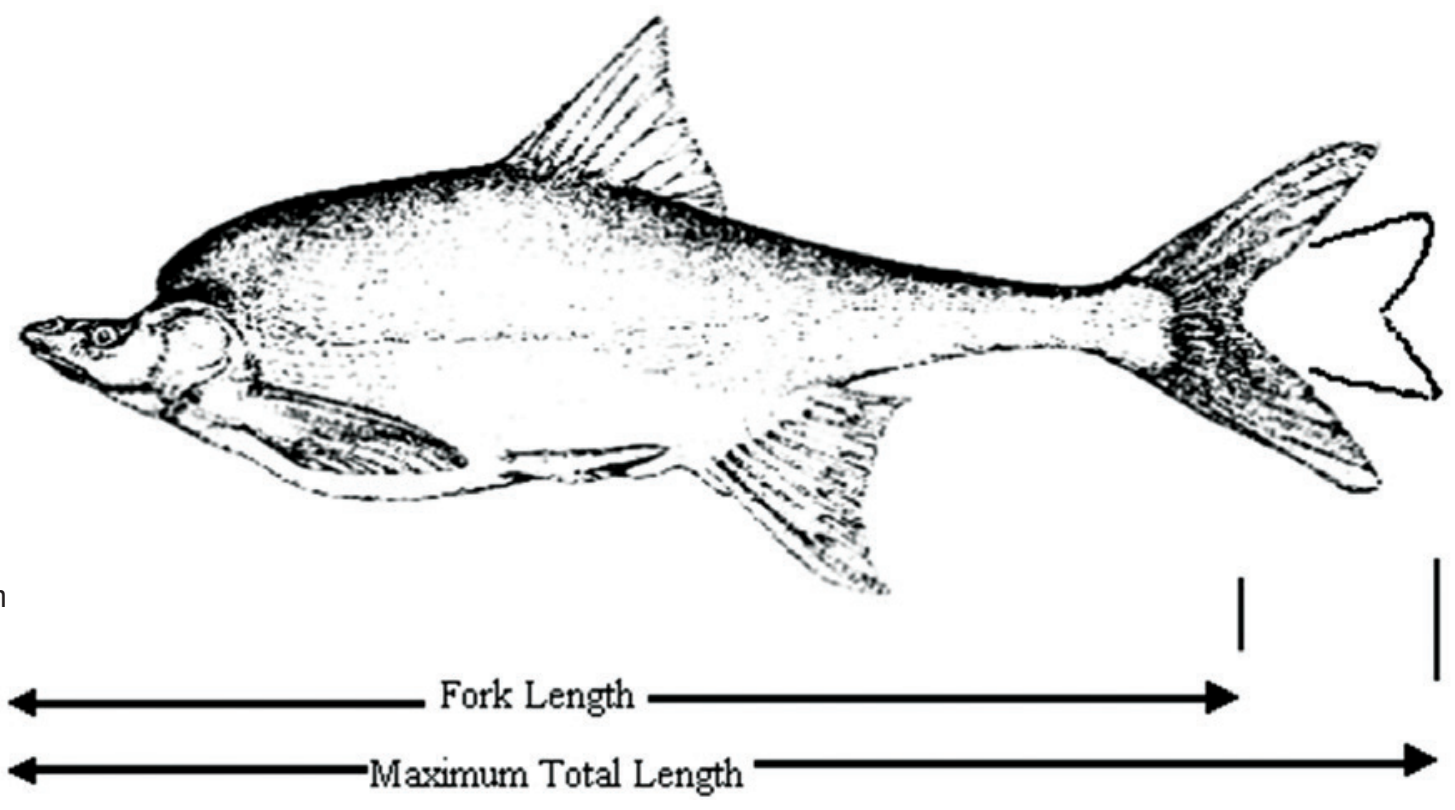

Figure 2. Photograph showing a PIT-tag insertion point in a humpback chub.

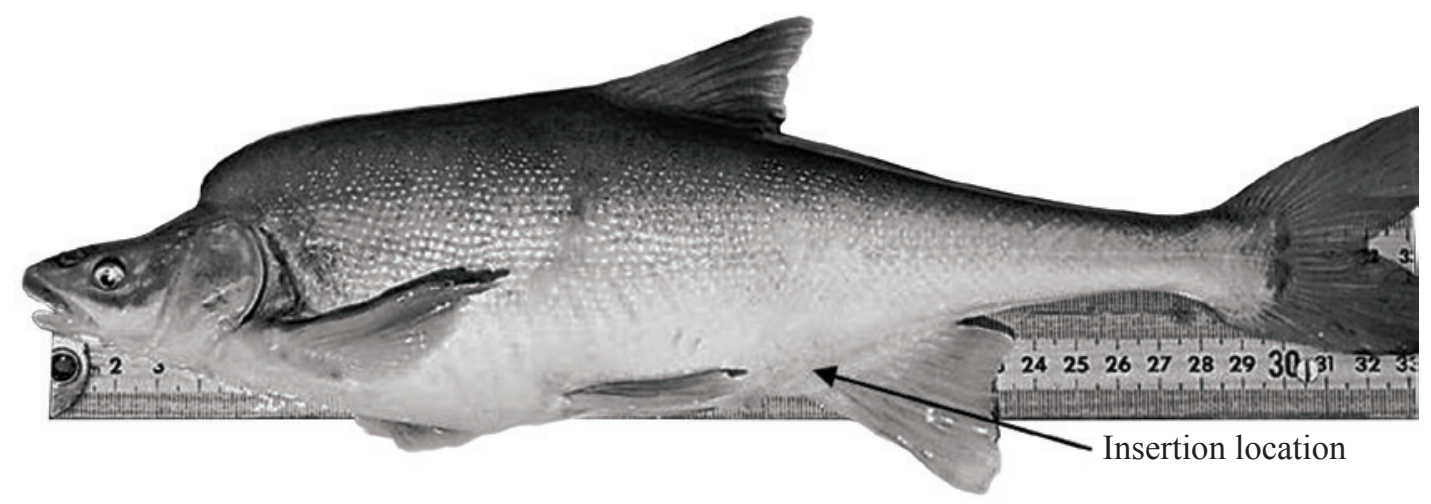


of a PIT tag, and those without a $134.2-\mathrm{kHz}$ tag should receive one. Native fish with only a $400-\mathrm{kHz}$ tag should receive a new 134.2-kHz tag, and both numbers should be recorded (fig. 3).

\section{Nonnative Fish}

All salmonids, catfish, and carp with a fin clip, and all rainbow trout between 100 and $250 \mathrm{~mm}$, should be scanned for the presence of a PIT tag. Measure FL of rainbow trout and TL of all other fish to the nearest millimeter and weigh each fish to the nearest gram when conditions allow. PIT-tagged rainbow trout caught during non-Natal Origins trips should be relatively uncommon; however, if such rainbow trout lack an adipose-fin clip, they should receive one.

Examine all:

-salmonids for the presence of an adipose- or pelvic-fin clip

- catfish for the presence of an adipose-fin clip

- common carp for the presence of a dorsal-spine or operculum clip.

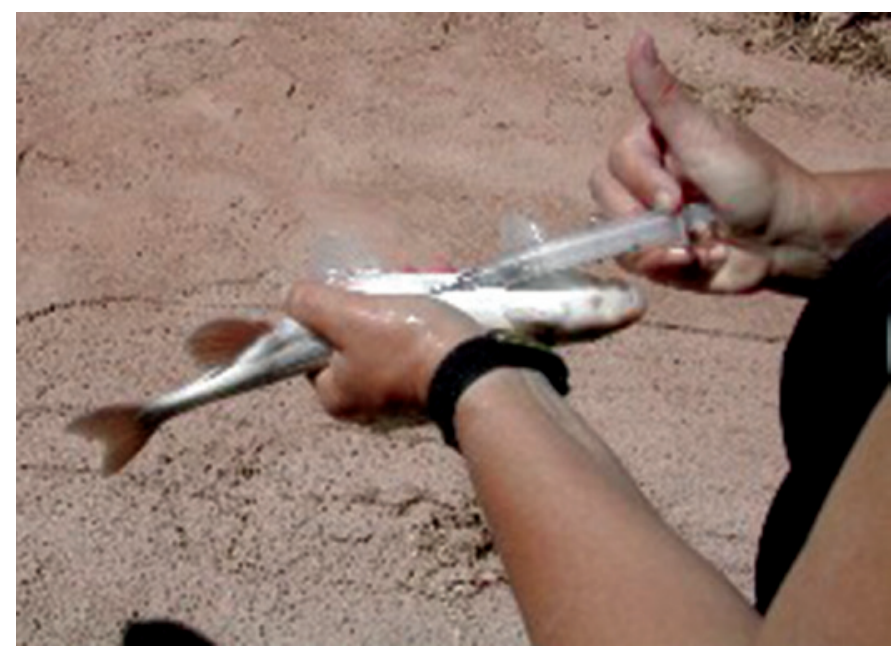

Figure 3. Photograph showing a PIT-tag insertion point in a sucker.
All salmonids, catfish, and carp with a fin clip, and all rainbow trout $80-250 \mathrm{~mm} \mathrm{FL}$, should be scanned for the presence of a PIT or Floy tag. Brown trout $>149 \mathrm{~mm}$ TL and all catfish $>99 \mathrm{~mm}$ TL without a PIT tag should be tagged and receive an adipose-fin clip. Common carp $>99 \mathrm{~mm}$ TL without a PIT tag should be tagged and receive a dorsal spine clip (see fig. 4). In previous years, all rainbow trout $>199 \mathrm{~mm}$ TL were Floy-tagged. For mark-recapture experiments during 2012, rainbow trout $>100 \mathrm{~mm}$ FL should be PIT-tagged and receive an adipose-fin clip.

During nonnative-fish-removal efforts, data on nonnatives will be collected as detailed above. Rainbow trout without a PIT tag will be removed alive from the river and transported to an appropriate stocking location to be identified by the AGFD. Rainbow trout that do have a PIT tag, and all common carp, will be returned alive to the river, and their return location will be recorded; all other nonnatives will be euthanized and preserved in accordance with the appropriate procedure.

\section{Protocols for the Little Colorado River}

The following protocols (see figs. 18, 19) apply to the Little Colorado River, including FWS population-estimation sampling in spring and fall, FWS translocation monitoring, AGFD lower-1,200-m monitoring, and any other sampling that may be conducted in the Little Colorado River from Blue Springs to the confluence with the Colorado River (Gloss and Coggins, 2005; Coggins and others, 2006; Bureau of Reclamation and U.S. Geological Survey Grand Canyon Monitoring and Research Center, 2010).

\section{VIE Tags}

Fish $<150 \mathrm{~mm}$ TL (suckers $<200 \mathrm{~mm} \mathrm{TL}$ ) should be scanned carefully for VIE tags. Record the recapture information, color, and body location of any VIE tags in the appropriate datasheet fields (see appendix entitled "VIE-Tag Color and Location Codes").
Figure 4. Photograph showing a PIT-tag insertion point in a rainbow trout.

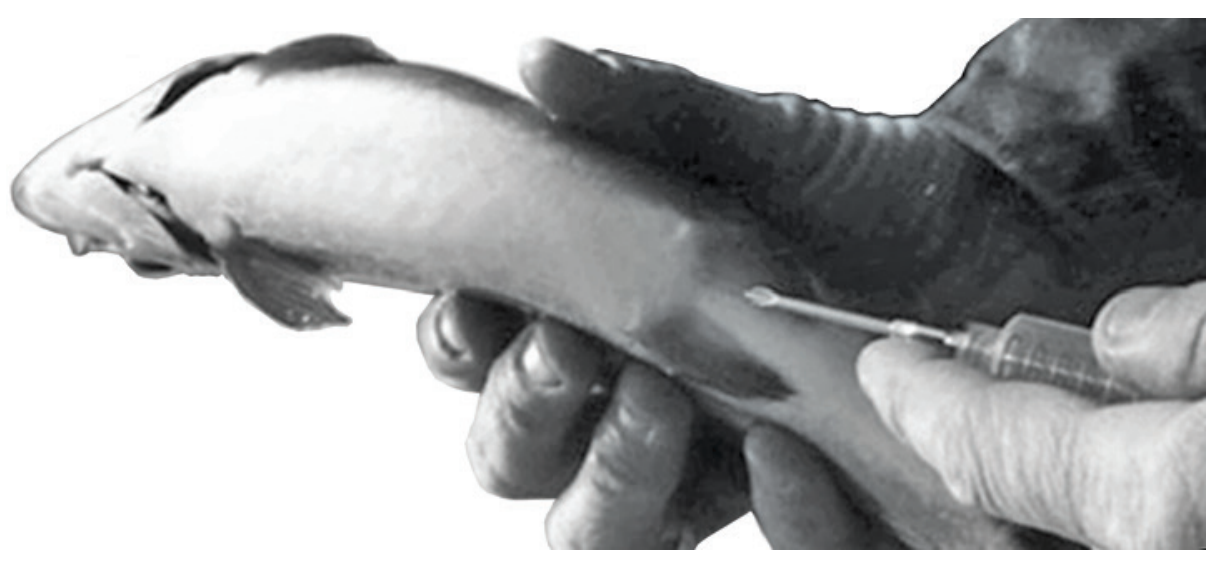




\section{Native Fish}

Measure TL of all native fish and FL of all large-bodied native fish to the nearest millimeter; FL for speckled dace need not be measured. Fish do not need to be weighed. Examine each fish carefully for fin clips, external parasites and sexual characteristics. All humpback chub $>80 \mathrm{~mm}$ TL and flannelmouth suckers and bluehead suckers $>149 \mathrm{~mm}$ TL should be scanned for the presence of a PIT tag. Any humpback chub over $80 \mathrm{~mm}$ TL without a 134.2-kHz tag should receive one, and any flannelmouth and bluehead sucker $>149 \mathrm{~mm}$ TL without a PIT tag should receive one. (See next subsection.)

\section{Special Conditions for Tagging Bluehead Suckers}

In some years, the FWS will catch large numbers of bluehead suckers during Little Colorado River hoopnetting trips. Cooperators have agreed that under such circumstances, it would be acceptable to PIT-tag a maximum of 900 and 400 bluehead suckers during spring and fall trips, respectively. Any more fish would be measured but would not receive a new PIT tag. Additionally, once these numbers have been met, a representative subsample of 50 fish may be measured and the rest counted if the biologist deems this step appropriate.

\section{Nonnative Fish}

Measure FL of rainbow trout and TL of all other species to the nearest millimeter. All small-bodied nonnatives should be scanned for the presence of VIE tags. Examine finclipped salmonids, catfish, carp, and all rainbow trout $>80$ $\mathrm{mm} \mathrm{FL}$ and $<250 \mathrm{~mm}$ FL and scan for the presence of a PIT or Floy tag. If not previously tagged, brown trout $>149 \mathrm{~mm}$ TL and all catfish $>99 \mathrm{~mm}$ TL should receive a PIT tag and receive an adipose-fin clip. Carp $>99 \mathrm{~mm}$ TL should receive a PIT tag and a dorsal-spine clip (see fig. 6).

\section{Length Measurement}

- $\quad \mathrm{TL}$ - measure length from the anteriormost part of the fish to the tip of the longest caudal-fin ray, with the lobes of the caudal fin pressed together (fig. 1).

- $\quad \mathrm{FL}$ - measure length from the most anteriormost part of the fish to the tip of the median caudal-fin ray.

Figure 5. Photograph showing a PIT-tag insertion point in a channel catfish.

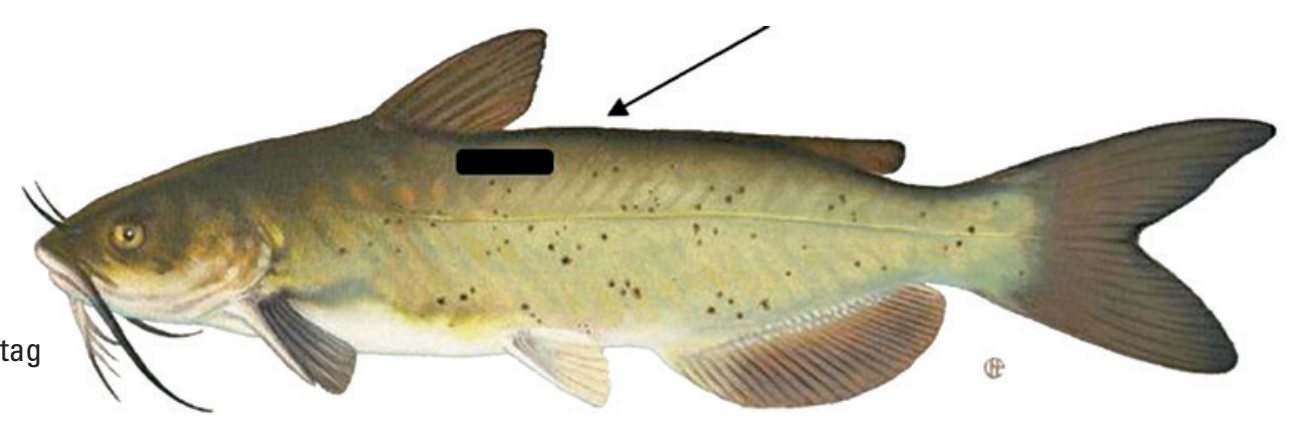

Figure 6. Photograph showing a PITtag insertion point in a common carp.

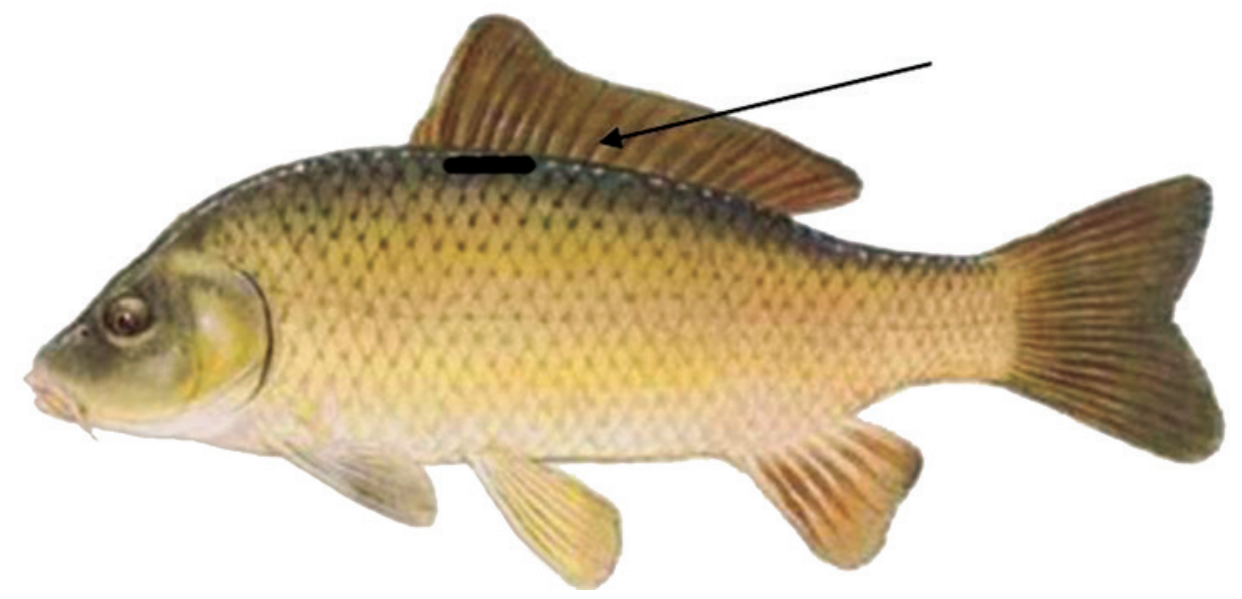




\section{Weight Measurement}

Record weight to the nearest gram; weigh fish only if it is not windy or raining and your equipment is functioning properly. Poor data are worse than no data, so do not collect a weight if you are not confident of its accuracy.

\section{PIT-Tagging Protocol}

All PIT-tag implants must be Biomark HPT12, $12.5-\mathrm{mm}, 134.2-\mathrm{kHz}$, ISO FDXB tags provided by the Grand Canyon Monitoring and Research Center. Do not use old 400-kHz tags!

All catfish and carp $>99 \mathrm{~mm}$ TL, humpback chub $>80 \mathrm{~mm}$ TL, brown trout $>149 \mathrm{~mm}$ TL, and all other native species $>149 \mathrm{~mm}$ TL (except for bluehead suckers under certain circumstances) without a $134.2-\mathrm{kHz}$ tag should receive one even if they already have an old $400-\mathrm{kHz}$ PIT or a Floy tag. Rainbow trout are also being PIT tagged on the Natal Origins project (see Project BIO 2.E.18 Bureau of Reclamation and U.S. Geological Survey Grand Canyon Monitoring and Research Center, 2010). When recording PIT tags, be sure to mention whether the fish is a recapture $(\mathrm{Y})$ or was not a recapture and was given a new tag $(\mathrm{N})$. Use a test tag to verify that readers are working before each use.

Ensure that PIT-tag readers are configured with the correct date and time stamp. Reader configuration needs to be done in the office using a personal computer before leaving for the field. Download the data from readers after each trip and transmit reader files to the Grand Canyon Monitoring and Research Center.

\section{Tips for Fish that May Have Multiple PIT Tags}

In the event that you catch a native fish $>300 \mathrm{~mm}$ TL and cannot detect a PIT tag with an FS-2001 "cheeseblock" reader, and you do not have a working $400-\mathrm{kHz}$ reader, $d o$ insert a new tag. If you suspect that a fish already has a new PIT tag (large fish or evidence of a PIT tag scar) but you are unable to detect the tag, the fish may have multiple tags that are nullifying each other. Multiple-tagged fish are not uncommon. Scan the fish by moving the reader wand in several different orientations. Place a test tag next to the fish and try rescanning the fish. If the reader fails to detect the test tag, the fish probably already has one or more PIT tags that are nullifying each other. Do not insert a new PIT tag into a fish that is believed to already have multiple tags, and note this observation on the datasheet (see fig. 20).

PIT-tag insertion points vary by species, as will be discussed further in the following subsections. Become familiar with PIT-tag-reader operation and ensure that readers are configured to scan and store tags.

\section{Best Practices for Keeping PIT Tags and Needles Sterile}

If you are using bulk PIT tags, soak tags in ethanol or isopropyl alcohol before use to check for broken tags (inside of tags will often change from copper color to red if broken). Return broken tags with lot IDs to Dave Foster, USGS Grand Canyon Monitoring and Research Center, 2255 N. Gemini Drive, Flagstaff, AZ 86001, 928-5567107 , as soon as the trip is off river. Some tags will scan even if the glass is broken, but they will fail over time.

If you are using bulk PIT tags, verify that the needle is sharp and clean. Biomark guidelines recommend that needles be changed every 10 fish. If you are using single needles for many fish, disinfect the needle and tag in 60 to 80 volume-percent ethanol or isopropyl alcohol. Needles should be cleaned between each use to remove adhering slime and scales that can be a path of infection between fish (Columbia Basin Fish and Wildlife Authority_-PIT Tag Steering Committee, 1999) Columbia Basin Fish and Wildlife Authority, 1999).

Starting in 2011, the Grand Canyon Monitoring and Research Center will provide Biomark preloaded sterile needles and MK-25 implant guns. Keep used needles in a safe container (for example, Nalgene bottle) and return used needles to the Grand Canyon Monitoring and Research Center for recycling.

\section{PIT-Tagging Humpback Chub}

1. Hold the fish with its abdomen up and its tail pointing toward you.

2. Insert the needle just posterior to the pelvic fin (fig. 2).

3. The insertion point should be on the abdomen of the fish to the right of the midventral line, with the tag placed posterior to the left pelvic girdle. The forward position of the pelvic fins on humpback chub allows the tag to be inserted higher on the abdomen than on other species.

4. The depth of needle penetration should be only enough to place the tag within the body cavity. Preliminary data from laboratory studies suggest that inserting the needle too far and perforating the intestine is the main cause of PIT-tag mortality (adapted from Biomark guidelines; visit http://www.biomark.com for the latest guidelines and training videos).

5. Do not PIT-tag small humpback chub that appear bloated because of the danger of perforating the intestine with the PIT-tag needle. 


\section{PIT-Tagging Suckers}

Use the same procedures for suckers as for humpback chub, or insert the PIT tag toward the tail of the fish under the left pelvic girdle (fig. 3). The needle should be directed posterior so that the tag is injected away from the heart and other vital organs.

\section{PIT-Tagging Trout}

Use the same procedures for trout as for humpback chub. Insert the PIT tag on the abdomen of the fish to the left of the midventral line, under the pelvic girdle (fig. 4).

\section{PIT-Tagging Catfish and Carp (Dorsal Musculature)}

1. Hold the fish with its abdomen down and the tail pointing toward you.

2. Insert the needle just posterior to the dorsal fin, to the left of the middorsal line (fig. 5). Scales may need to be removed from carp at the insertion point of the tag (fig. 6).

3. The depth of insertion should be only enough to place the PIT tag inside the dorsal musculature.

\section{Verifying PIT Tags}

Unacceptable errors can be made when transcribing and entering PIT tags into computer databases. The following procedures help to minimize errors that may occur when transcribing and entering PIT tags:

- Verify that the PIT-tag reader is turned on and in "scan/ store" mode.

- Scan the fish for tags.

- Read and record the entire 10- to 14-digit code using words instead of letters to avoid confusion between letters and numbers that sound alike. For example, tag code $12 \mathrm{~A} 3 \mathrm{~F} 45 \mathrm{E} 6 \mathrm{~B}$ should be read as "one, two, alpha, three, foxtrot, four, five, echo, six, bravo."

- Always cross zeros when recording PIT tags to distinguish a zero from a "D" on a datasheet. When recording PIT tags, draw a horizontal line above any letters in the tag number (fig. 7) to distinguish letters from numbers that can easily be confused (for example, B and 8, D and $0, \mathrm{~S}$ and 5).

- The data recorder will repeat the tag code back to verify that it has been recorded correctly.

- Be sure to record whether the fish is a recapture (Y) or not $(\mathrm{N})$.

\section{Floy-Tagging Protocol}

Rainbow trout are the only fish in the mainstem Colorado River that should receive a Floy tag for mark-recapture experiments. Floy tags, also known as T-Bar anchor tags, should be inserted just below the dorsal fin (fig. 8). Scales should be removed first at the insertion point of the tag. Insert the tag at an acute angle to the body so that the tag lies next to the body when the fish swims. Insert the needle far enough to pass the midline but not to puncture the opposite side. Be sure to place the anchor behind the pterygiophores to prevent excessive tag loss (Waldman and others, 1990). Twist applicator $90^{\circ}$ to dislodge the tag from the applicator before removing the needle from the fish.

\section{Fin-Clipping Protocol}

- Fins should be clipped at the base and completely removed from all fish that receive a fin clip. Fin clip codes should reference the side of the fish and the fin location (fig. 9; see appendix A, "datasheet codes").

- The adipose fin should be clipped at the base and completely removed from all rainbow trout in the Lees Ferry reach that receive a Floy tag (fig. 10). Again, Floy tags should be used only for short-term mark-recapture experiments. Use yellow "AGFD" Floy tags in the Lees Ferry reach, and gray "USGS" Floy tags downstream from Lees Ferry.

- As part of short-term mark-recapture experiments, rainbow trout downstream of Lees Ferry that receive a "USGS" gray Floy tag should also receive a left pelvic-fin (LP2) clip. Clip pelvic and pectoral fins at the base, removing the entire pelvic or pectoral fin.

- All brown trout $>149 \mathrm{~mm}$ TL and catfish $>99 \mathrm{~mm}$ TL should receive a PIT tag and an adipose-fin clip.

- Common carp receiving a PIT tag should also receive a dorsalspine clip.

Figure 7. Example of horizontal lines over letters when recording PIT-tag numbers on a datasheet.

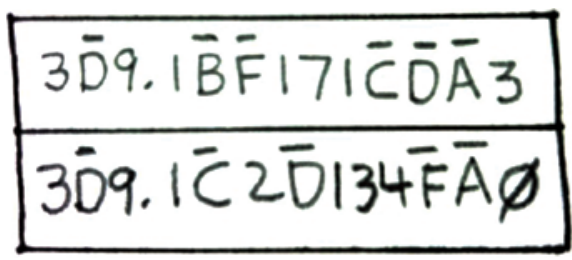

Figure 8. Diagram showing Floy-tag insertion point at base of dorsal fin between pterygiophores.

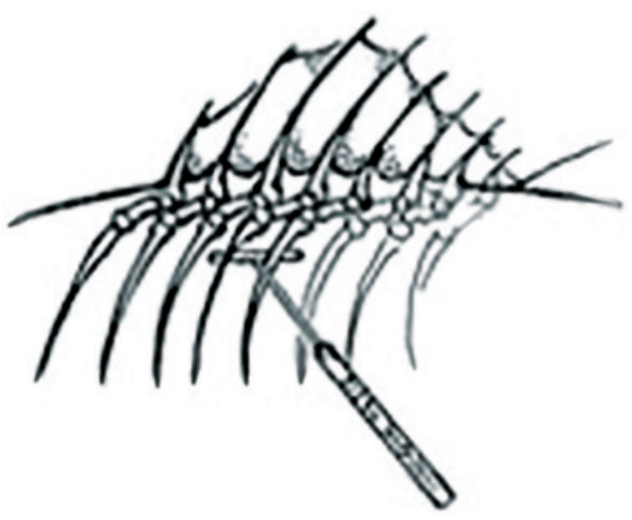




\section{VIE Tags}

Several colors of VIE tags have been placed in humpback chubs and other fish as a part of the Near Shore Ecology project. Marks were placed around all fins, operculum, and snout (fig. 11). All fish $>40 \mathrm{~mm}$ and $<149$ mm TL (suckers $<200 \mathrm{~mm}$ TL) should be scanned for the presence of VIE tags. Fish captured in the Little Colorado River and in the mainstem near the Little Colorado River confluence and downstream to Unkar Creek Rapid should be carefully examined because all fish captured by the Near Shore Ecology project were tagged in this reach of the river. Colors should be compared to color standards provided by the Grand Canyon Monitoring and Research Center.
Figure 9. Drawing showing fins and their corresponding codes on left side of humpback chub (from http://www. coloradoriverrecovery.org/generalinformation/the-fish/humpback-chub. html).
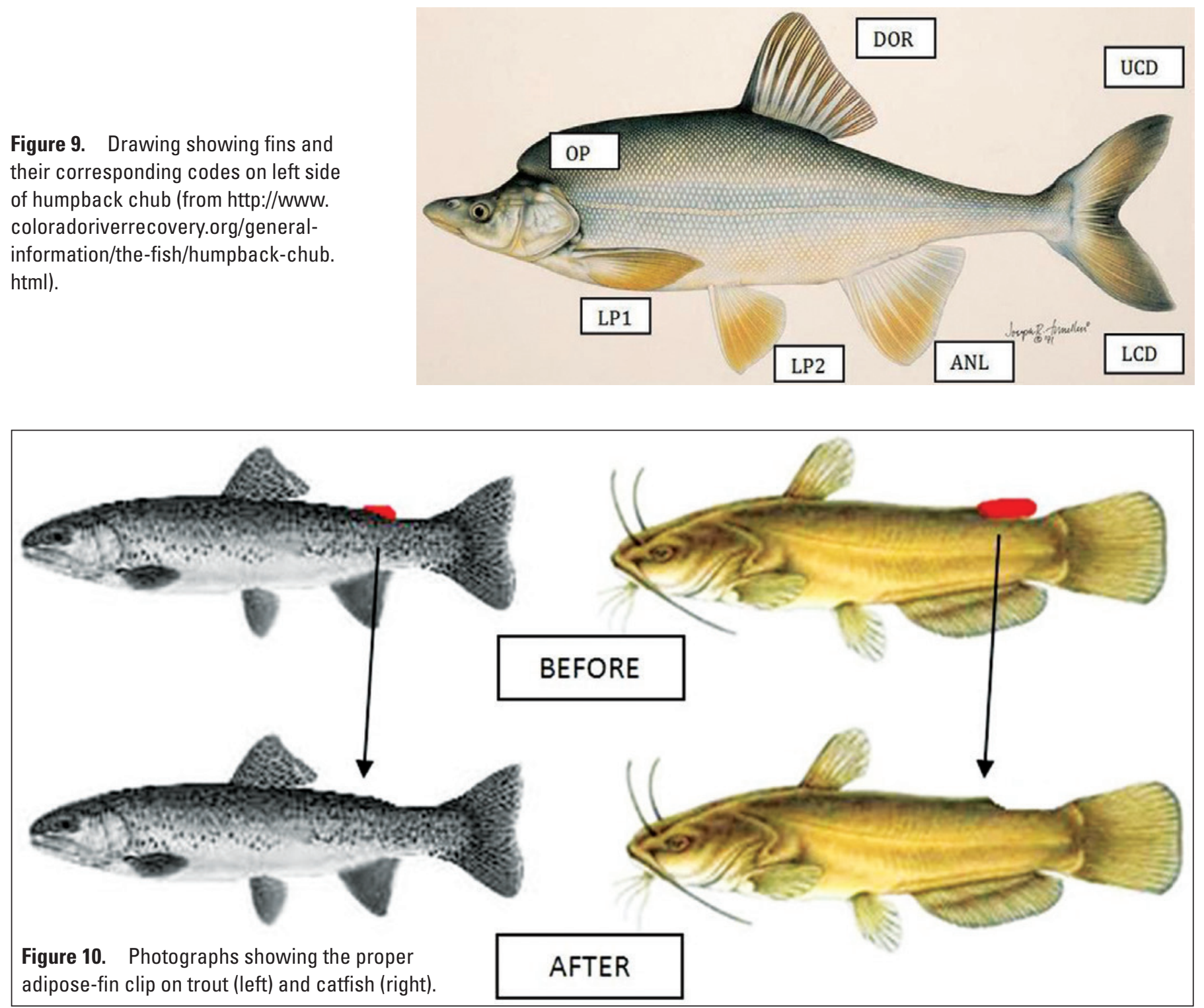

Figure 11. Line drawing showing possible location codes for visible implant elastomer tag: $A N$, anal fin; CD, caudal fin; DR, dorsal fin; FD, forward dorsal fin; $R D$, rear dorsal fin; $H D$, head, $L P$, lip; $P 1$, right pelvic fin; P2, left pelvic fin. .

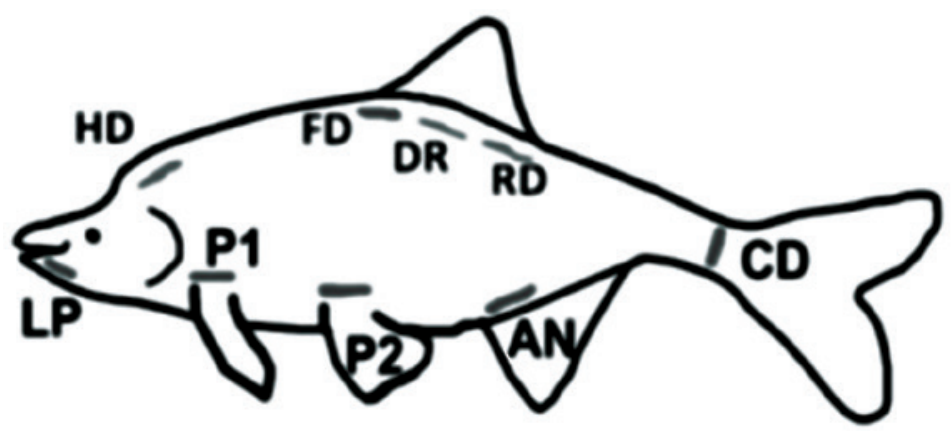




\section{VIE-Tag Colors, Locations, and Coding}

Codes for VIE tag colors and locations should be reported color first, then side, and then location. For example, an orange VIE tag located by the left pelvic fin would be recorded as "OLP2." Codes for VIE-tag color and location are listed in appendix A ("Field Datasheet Codes").

\section{Angling Protocol}

Standardized angling in the Grand Canyon consists of three anglers fishing for 20 minutes, for a total of 60 anglerminutes per site. Spinning rods are outfitted with 10-poundtest monofilament line, a 1/2-ounce (14 gram) egg sinker, a barrel swivel, and a no. 6 Eagle Claw baitholder hook baited with half a worm. The setup is fished by using a Carolina rig where the egg sinker is slipped on to the main line then a barrel swivel is attached. A leader of 8 to 10 inches (in) of 10-pound-test monofilament line with a no. 6 Eagle Claw hook attached on one end is then attached to the other end of the barrel swivel (fig. 12).

\section{Guidelines for Recording Data}

- If you do not record data in the field, you will unlikely be able to reconstruct them in the office. It is better to record too much information on a datasheet than to return to camp or the office and try to reconstruct it. Take your time and record clean data. It is better to have correct data than a lot of data with irresolvable problems.

- Proper recording of data is the most important aspect of field research. You may feel pressured to process fish quickly, especially when catches are high. Remember that you can process fish only as fast as the recorder can accurately record legible data. If you proceed too quickly, the data get sloppy. If your handwriting is illegible, the data are basically lost. Communicate with your data recorder and ask whether you are going too fast. Data recorders must stop the fish processor if they are going too fast.
- Do not forget to record "Y" or " $\mathrm{N}$ " in the recapture field. Do not assume that the data recorder is observing whether you are injecting a tag or not. Each mistake can be costly during analysis. Slow down in the field and ensure that the recapture field is filled in. Examine datasheets daily to verify that data recording problems are not occurring.

- Where possible, record Global Positioning System (GPS) waypoints on the datasheet and the serial number from the GPS unit being used. If you cannot obtain a waypoint, note it on the datasheet.

- A blank data field indicates that the fish was not checked. Be sure to fill in all columns of the datasheet and note whether such things as parasites or ripeness were checked: blank = you didn't check; "undetermined" = you checked but couldn't make a distinction.

\section{Standard Data Label for Preserving Specimens}

Fill out all sample information on write-in-the-rain paper with a pencil only. Label all preserved specimens so that they can be clearly linked to the datasheet (fig. 13).

\begin{tabular}{ll}
\hline Trip ID & LC20120622 \\
Biologist & Engelbert Humperdinck \\
Sample site & Camp and net in LCR (Site at LF and mainstem, NSE use Site-HSU) \\
River & LCR \\
Date & June 25, 2012 \\
Time & 1630 \\
Mile & RM in mainstem, RKM upstream from the mouth in Tributaries \\
Gear & HB (Hoopnet baited) \\
Species & STB \\
Length & 85 mm \\
Weight & 35 g \\
Sample id & (what preserved) Try to keep Sample_IDs unique during a trip. \\
Preservative & Formalin, Ethanol, etc. \\
\hline
\end{tabular}

Figure 13. Example of properly completed sample data label.

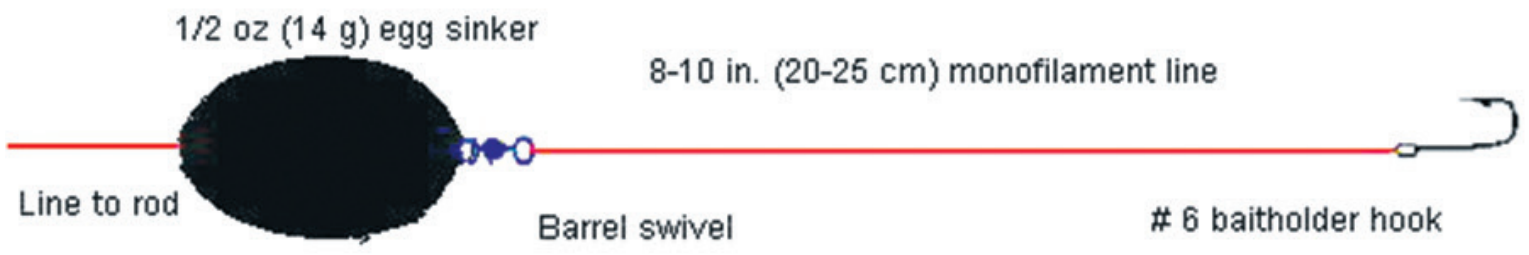

Figure 12. Picture of Carolina rig used for standardized angling sampling. 


\section{Preserving Humpback Chub}

All dead humpback chub must be saved and preserved in ethanol. Humpback chub too large to preserve whole should have their heads and gut contents preserved in ethanol. At the very least, otoliths should be extracted before bacterial decomposition compromises potential microchemical analyses.

\section{Bite Mark Documentation}

Record any bite marks observed on all native fish in the comments section of the datasheet. If possible, photograph and describe suspected bite marks. If you have photographed the fish, title the photograph with the species and date (for example, "HBC06122012") so that multiple photographs can be distinguished from each other upon return to the office. Note the photograph title in the comments section of the datasheet.

\section{Native fish in Lees Ferry}

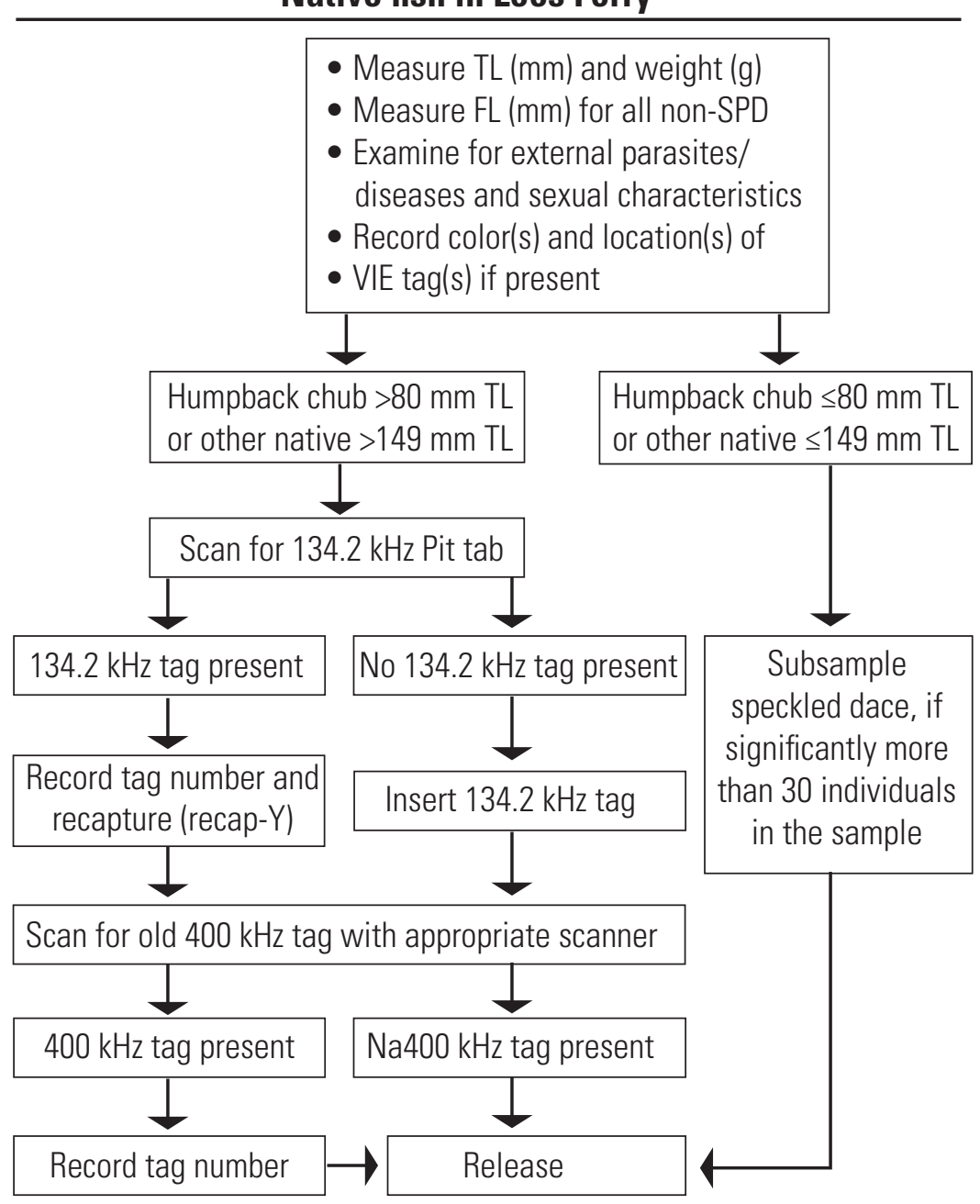

Figure 14. Flow chart showing native fish handling and tagging guidelines at Lees Ferry. 


\section{Parasite/Disease Documentation}

Record any visible parasites and diseases (see appendix A, "Field Datasheet Codes"). If a parasite or disease is unknown or in question, take a photograph and write detailed comments on the datasheet for further examination later. Include a piece of paper in the photograph with enough information to link it with the fish datasheet, or record information about the camera (model, owner, image numbers) on the datasheet so that the photograph can be linked to the fish.
If you see anchor worms (Lernaea) do not remove them from the fish (R. Cole, National Wildlife Health Center, USGS, written commun., 2009). Removal can create an open wound and lead to infection. Anchor worms may also provide a biological marker indicating that the fish was in warm water (for example, the Little Colorado River) long enough for the parasite to develop. This information might help to establish the recent history of the fish. If Asian tapeworm (Bothriocephalus acheilognathi, commonly found in humpback chub in the Little Colorado River) is suspected and a small fish appears to be bloated, do not PIT-tag.

\section{Nonnative fish in Lees Ferry reach}

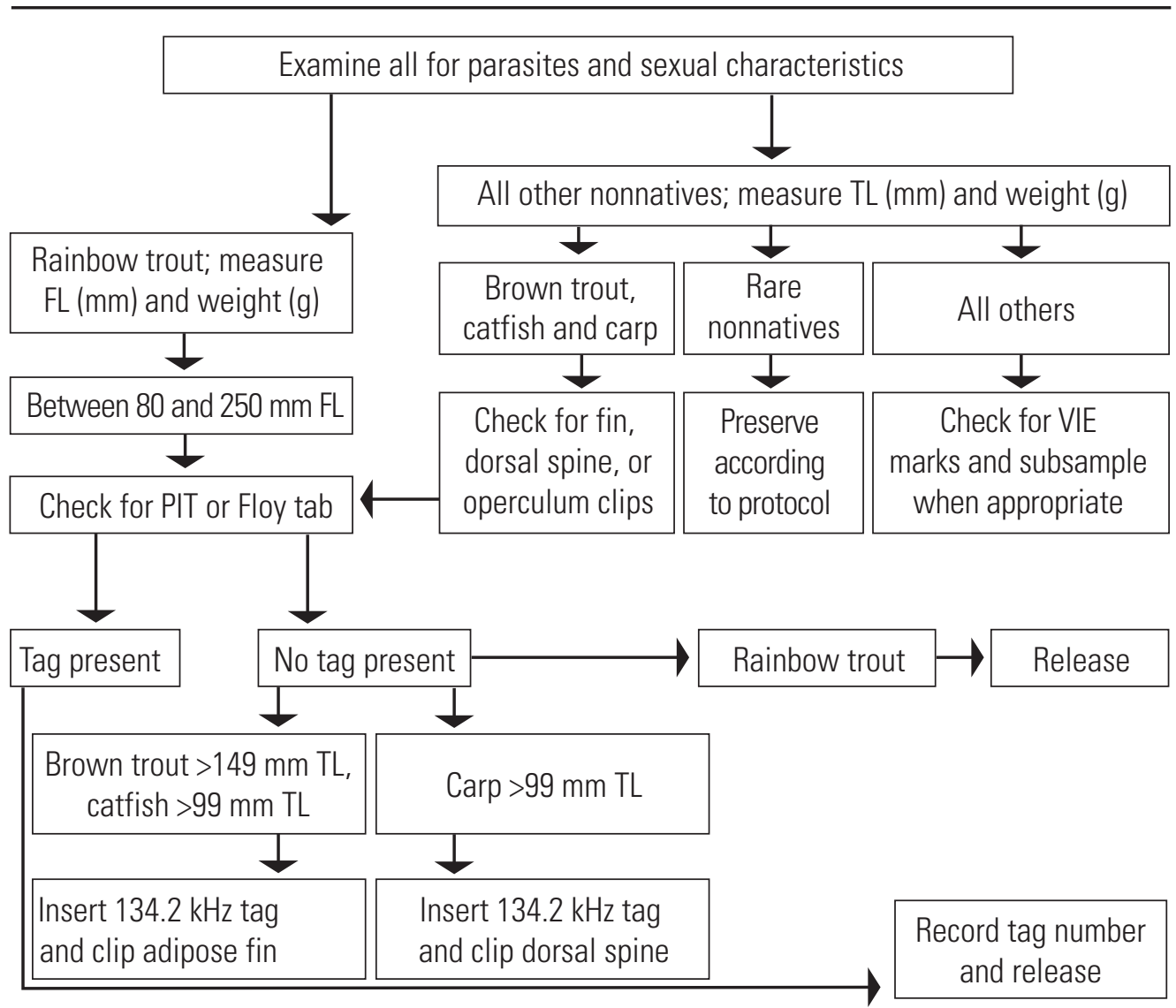

Figure 15. Flow chart showing nonnative fish handling and tagging guidelines at Lees Ferry. 


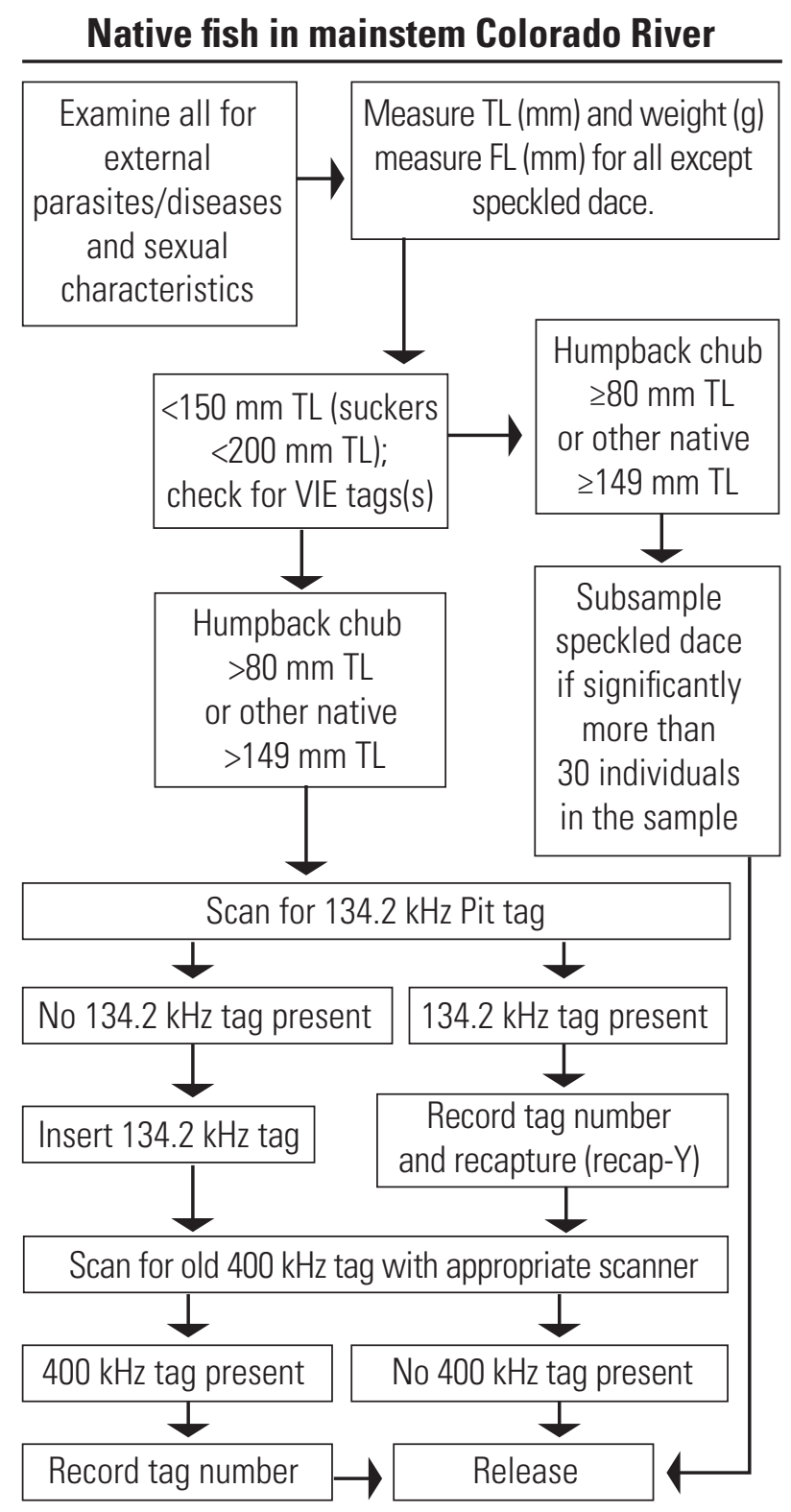

Figure 16. Flow chart showing native fish handling and tagging guidelines in mainstem Colorado River downstream of Lees Ferry. 
Figure 17. Flow chart showing nonnative fish handling and tagging guidelines in mainstem Colorado River downstream of Lees Ferry.

\section{Nonnative fish in mainstem Colorado River}

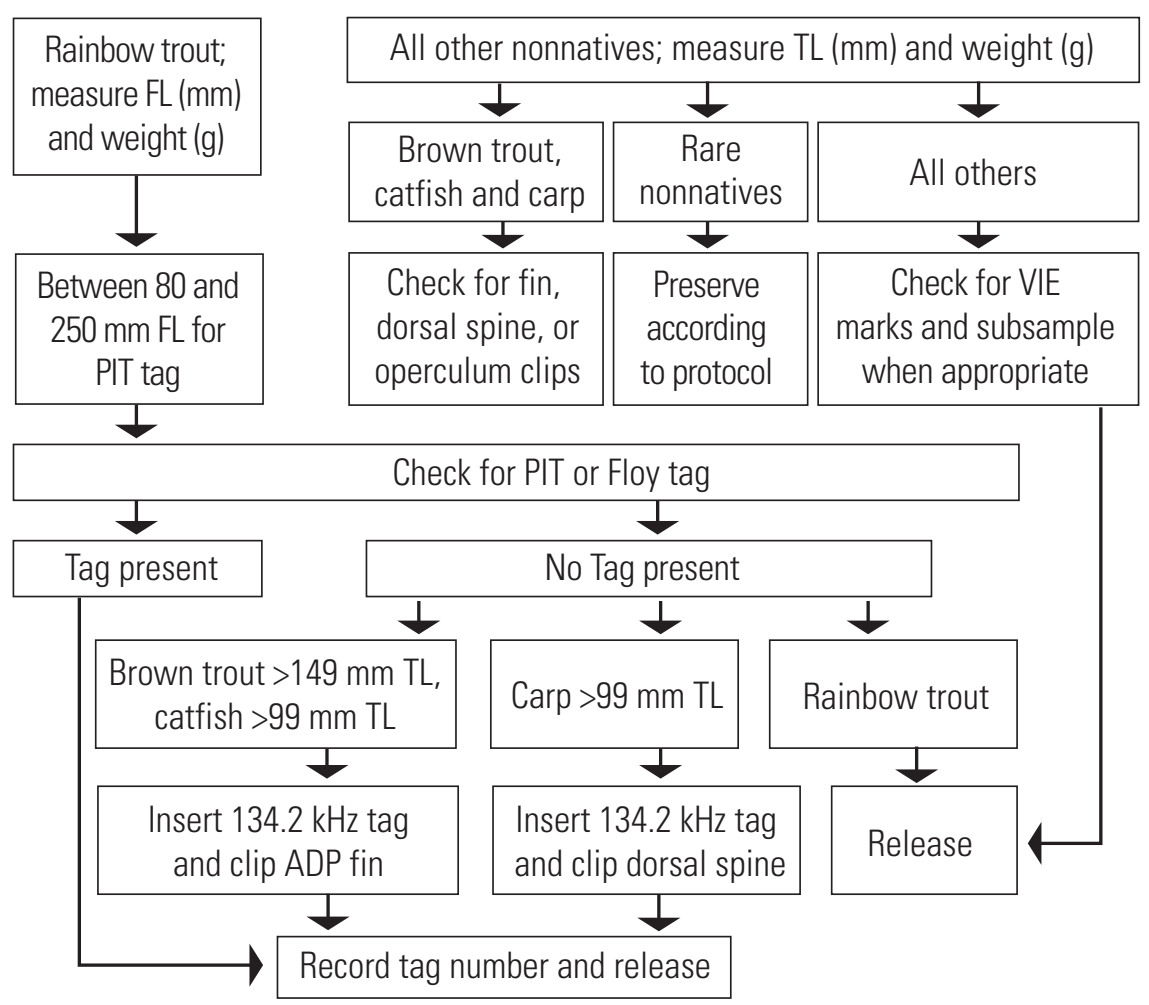

\section{Native fish in Little Colorado River}

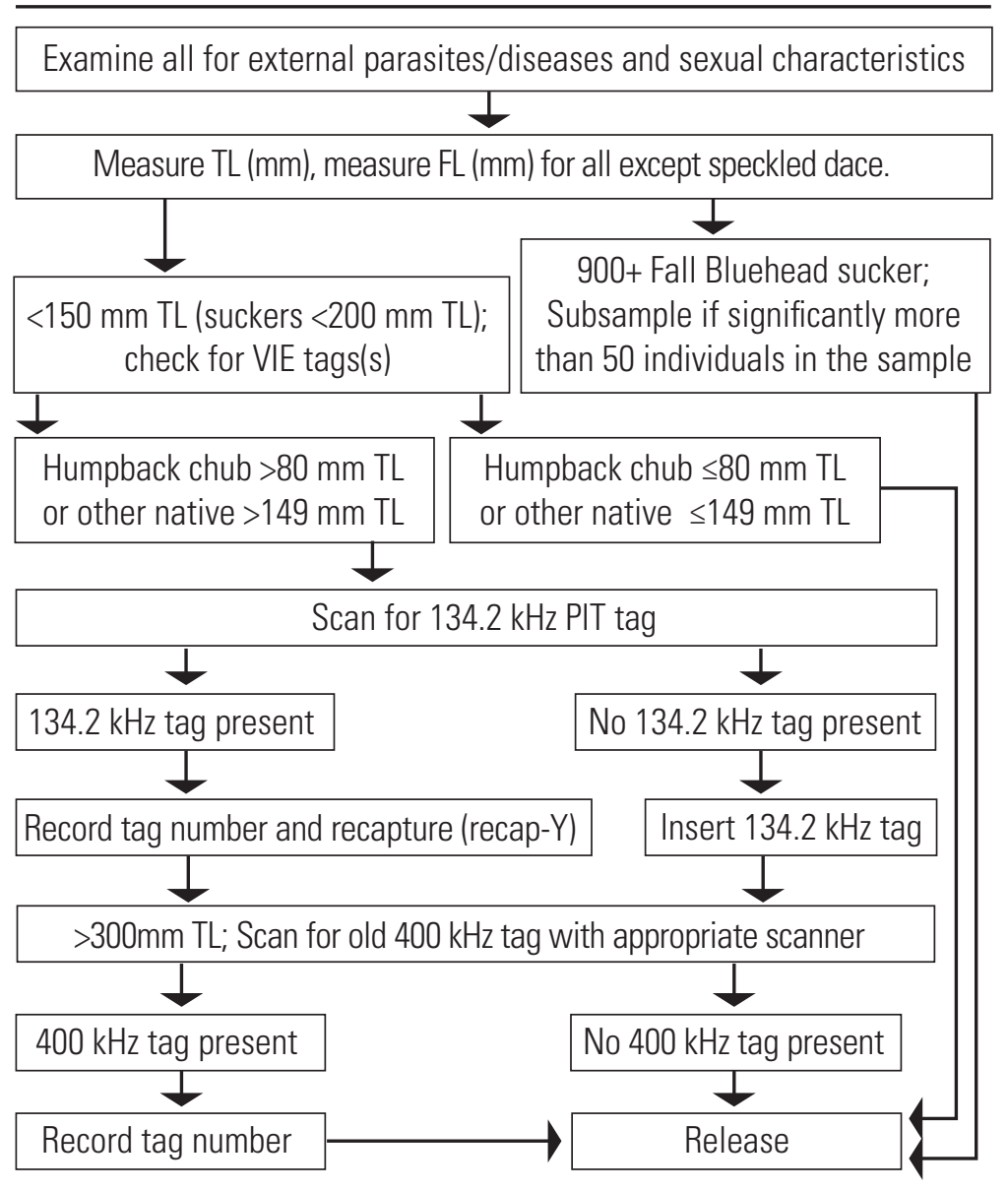

Figure 18. Flow chart showing native fish handling and tagging guidelines in the Little Colorado River. 
Figure 19. Flow chart showing nonnative fish handling and tagging guidelines in the Little Colorado River.

\section{Nonnative fish in Little Colorado River}

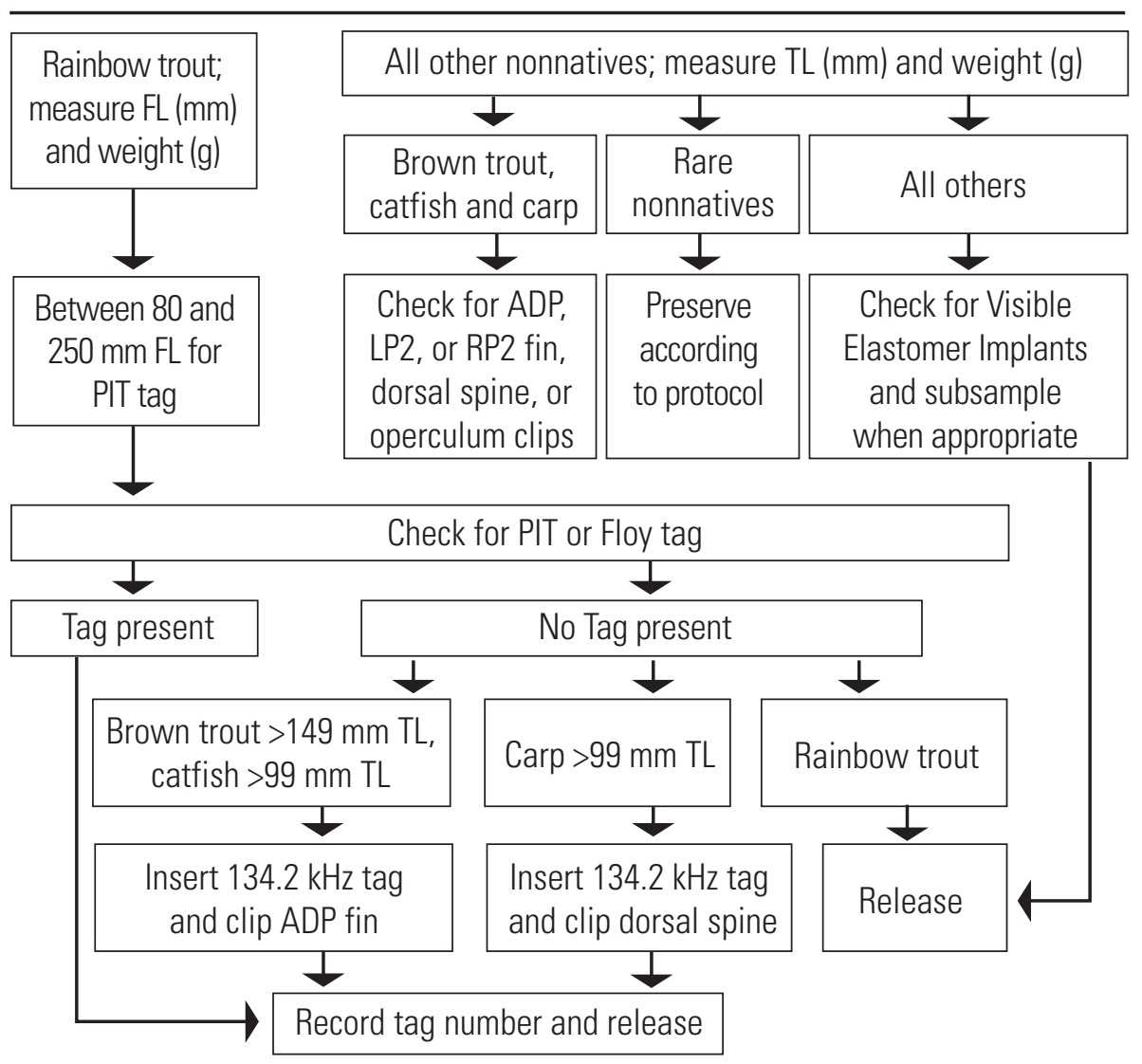

Figure 20. Flow chart showing decision tree for PIT tagging fish which may have multiple tags.

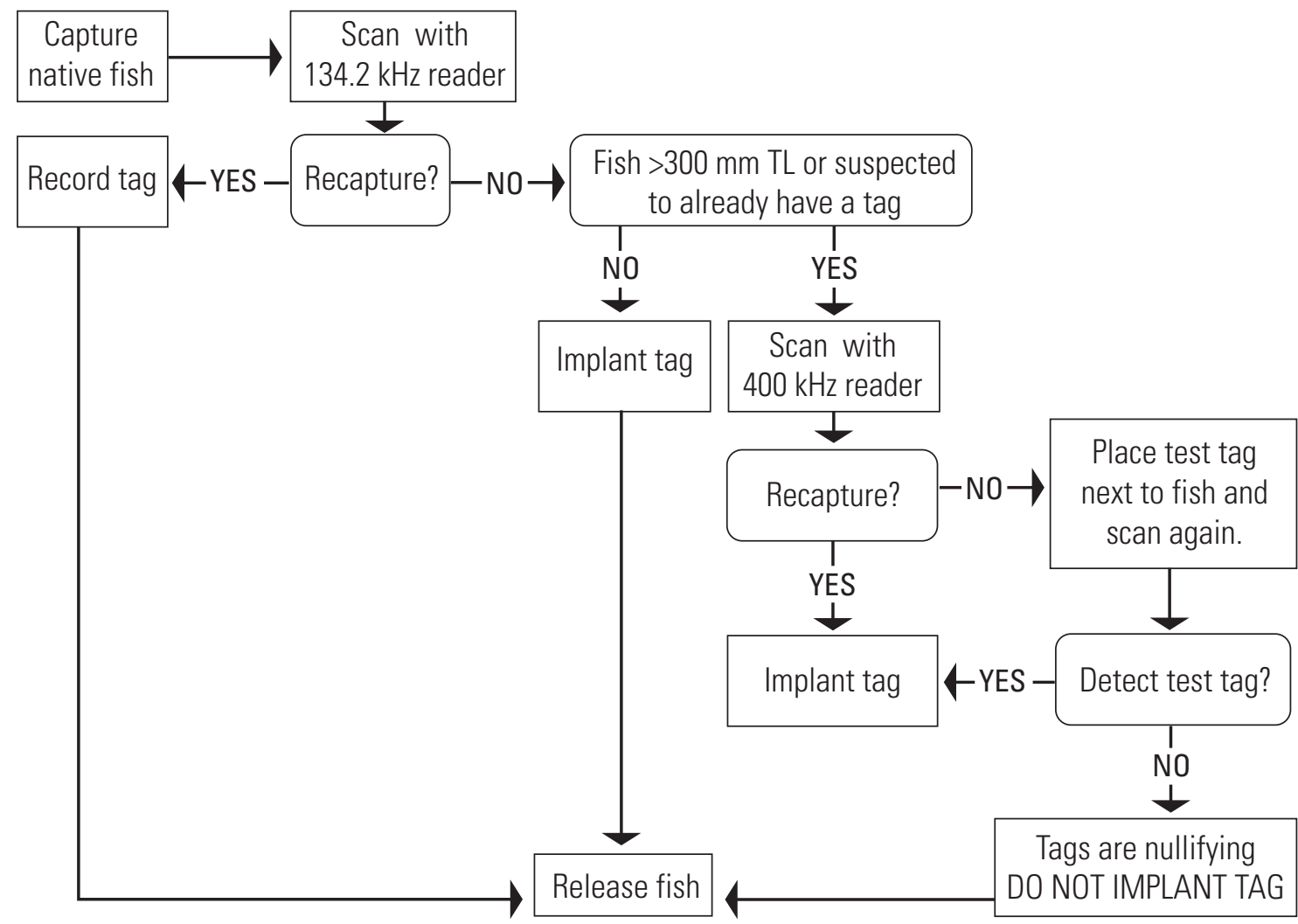




\section{Document Revisions}

\section{Fall 2002}

- Discontinued baiting hoopnets after laboratory studies revealed that PIT-tagging of recently-fed fish led to high mortality.

- Native fish $>150 \mathrm{~mm}$ TL without a PIT tag received one, and dorsal fin was punched as a secondary mark to evaluate tag loss.

- September trip received a left-pelvic-fin clip. Fish 100 to $149 \mathrm{~mm}$ TL caught during the Little Colorado River October trip received a left-pelvic-fin clip if they did not already have one and a right-pelvic-fin clip if the left pelvic fin was previously clipped to get an early estimate of recruitment.

\section{Spring 2003}

- Started PIT-tagging previously untagged native fish with the new $134.2-\mathrm{kHz}$ tags.

- Started PIT-tagging all carp $\geq 150 \mathrm{~mm}$ TL.

- Experimented with the use of elastomer dye to mark suckers.

- Chub translocated above Chute Falls were tagged with elastomer dye.

\section{September 2003}

- Started PIT tagging all chub $\geq 100 \mathrm{~mm}$ TL and all other native fish $\geq 150 \mathrm{~mm}$ TL. Fish with $400-\mathrm{kHz}$ PIT tags were double-tagged with new $134.2-\mathrm{kHz}$ tags.

- Discontinued taking weights on humpback chub to reduce handling.

\section{November 2003}

- PIT-tagging size for any species of fish is $\geq 150 \mathrm{~mm}$ TL until further notice, but humpback chub $>100 \mathrm{~mm}$ still need to be scanned for the presence of a PIT tag.

- No weighing of fish until further notice. Trout projects downstream and in Lees Ferry will experiment with new types of scales and attempt to find equipment that will work better under field conditions.

- 400-kHz PIT tags will no longer be inserted in any fish downstream of Lees Ferry.

- Brown trout caught on downstream trips will now receive a 134.2-kHz PIT tags at

- $\geq 150 \mathrm{~mm}$ TL instead of $120 \mathrm{~mm}$ TL as previously. Do not insert a $134.2-\mathrm{kHz}$ PIT tag into brown trout if they already have an old 400-kHz PIT tag.
- All chub in the Little Colorado River must be examined for yellow VIE tags with blue light and amber glasses. VIE tags are located in the dorsal musculature near the dorsal insertion on the left side of the fish.

- Mainstem trips are not required to use blue light and amber glasses to scan for VIE tags in chub.

- VIE dyes will no longer be used as a secondary mark to evaluate tag loss in suckers, but be sure to record whether you see pink or green VIE tags in the head of suckers.

- In the event that you catch a humpback chub $>350 \mathrm{~mm}$ TL, cannot get a read with the new PIT-tag reader, and you do not have a working old reader, do not insert a new PIT tag - just record and release.

\section{August 2004}

- All data submitted to the Grand Canyon Monitoring and Research Center should include all digits and the period for new PIT-tag numbers, for example, "3D9.1BF4A3C2E."

\section{March 2005}

- It has been 2 years since any fish $100 \mathrm{~mm}$ TL have been tagged. Fish between 100 and $149 \mathrm{~mm}$ TL no longer need to be scanned for PIT tags. Any fish previously tagged (in 2003 ) at $100 \mathrm{~mm}$ TL would now be $>150 \mathrm{~mm}$ TL.

\section{December 2005}

- Take otoliths from all catfishes and centrarchids. Preserve in ethanol, include vial label, and record on nonnative datasheet (bottle number).

- Take 20 to 30 catfish samples when possible (spines, otolith). If catfish are similar in size, take a subsample of spines and otoliths.

- Check all catfish stomachs for the presence or absence of fish remains (in the field).

- Bring all warmwater nonnatives (bass and so on) back to the office, whole when possible. Preserve in ethanol and cut open stomach cavity to allow internal organs to be preserved.

- If species is too large to bring back whole, take stomachs and otoliths (preserved in ethanol). Take scales from posterior side of pectoral fin below or above lateral line (dry preservation), as well as a fin clip (also preserved in ethanol).

- Disposition code is "DP" if specimen is preserved.

- Record all information on datasheets (date, disposition, location [river mile], bottle numbers, and what was removed and (or) preserved). 


\section{January 2009}

- $\quad$ PIT-tag humpback chub $>99 \mathrm{~mm}$ TL rather than $149 \mathrm{~mm}$ TL unless fish is bloated or appears to have Asian tapeworm.

- Check for VIE tags on all fish <149 mm TL.

- Soak PIT tags in ethanol to check for broken tags in the field.

- Document rare nonnative fish in writing to Kara Hilwig, Grand Canyon Monitoring and Research Center, with associated sample(s) taken.

- FWS will PIT-tag a maximum of 900 bluehead sucker $>149 \mathrm{~mm}$ TL during the first spring sampling trip and a maximum of 400 bluehead sucker during fall sampling trips. All other bluehead suckers will receive an LP2 clip.

- In the event that you catch a native fish $>300 \mathrm{~mm}$ TL and cannot get a PIT-tag code with the new scanner, then scan the fish with a test PIT tag held next to it. If you detect the test tag, then insert a new PIT tag. If you do not detect the test tag, then the fish is likely double tagged, and so do not insert another tag.

- Standardized angling effort and gear throughout canyon.

- Record bite marks in comments section on datasheet.

\section{March 2011}

- Edited document for clarity and to avoid redundancy.

- Revised figures to clarify tagging procedures.

- Added information on VIE-tag color and location coding.

- Clarified that all rainbow trout should be Floy tagged. The Grand Canyon Monitoring and Research Center will provide Floy tags and guns to the Near Shore Ecology project.

- Starting in 2011, the Grand Canyon Monitoring and Research Center will provide Biomark preloaded sterile needles and MK-25 implant guns. Keep used needles in a sharps container (such as a Nalgene bottle) and return to the Grand Canyon Monitoring and Research Center for recycling.

\section{March 2012}

- Changed tagging protocol for bluehead suckers in the Little Colorado River. Only a subset of bluehead suckers will be PIT tagged by the FWS in the Little Colorado River.
- FL of rainbow trout will be measured to accommodate the Natal Origins project.

- All rainbow trout 80 to $250 \mathrm{~mm}$ FL will be scanned for PIT tags to accommodate the Natal Origins project.

- All rainbow trout with an adipose-fin clip will be scanned for a PIT tag.

- Added alternative nonnative-fish-handling procedure for mechanical-removal efforts.

- Updated VIE tag location table and figure.

- Changed contact person for preserved nonnative specimens to David Ward, USGS Grand Canyon Monitoring and Research Center, 2255 N. Gemini Drive, Flagstaff, AZ 86001, telephone (928) 556-7280.

- Except for mark-recapture experiments, fish will no longer be Floy tagged in Lees Ferry or downstream.

- Updated flowchart figures.

- Updated all field codes on datasheets for consistency with latest version of Access data-entry template (2012_02_08).

\section{January 2015}

Changed length of humpback chub to PIT tag or check for PIT tag presence from $>=99 \mathrm{~mm}$ TL to $80 \mathrm{~mm}$ TL to allow for PIT tag insertion into smaller humpback chub. See Ward and others (in press) for documentation and justification of this change.

\section{Acknowledgments}

Development of these standardized methods has been a group effort taking place over several years. We are especially grateful for contributions by Aaron Bunch, Mike Anderson, Robin Osterhoudt, Brian Cark, Pilar Woltors, and Andy Makinster of the AGFD; D.R. Van Haverbeke, Dennis Stone, Pamela Sponholtz, and Mike Pillow of the FWS; Brian Healy and Emily Omana of the NPS with Grand Canyon National Park; Josh Korman of Ecometric, Inc.; Bill Pine of the University of Florida; and Scott Vanderkooi, Michael Yard, Kyrie Fry, and Meredith Hartwell of the USGS Grand Canyon Monitoring and Research Center. 


\section{References Cited}

Anderson, R.O., and Neumann, R.M., 1996, Length, weight, and associated structural indices, in Murphy, B.R., and Willis, D.W., eds., Fisheries techniques (2d ed.): Bethesda, Md., American Fisheries Society, p. 447-481 [http://www. fw.vt.edu/murphybr/web/Readings/Anderson $\% 20$ and $\% 20$ Nuemann.pdf, accessed December 22, 2010].

Coggins, L.G., Jr., Pine, W.E., III, Walters, C.J., Van Haverbeke, D.R., Ward, D., and Johnstone, H.C., 2006, Abundance trends and status of the Little Colorado River population of humpback chub: North American Journal of Fisheries Management, v. 26, no. 1, doi: 10.1577M05075.1, p. 233-245 [http:/www.usbr.gov/uc/rm/amp/twg/ mtgs/06may24/Attach_06f.pdf, accessed July 19, 2011].

Columbia Basin Fish and Wildlife Authority_PIT Tag Steering Committee, 1999, PIT tag marking procedures manualversion 2.0: Portland, Ore., 22 p. [http://php.ptagis.org/wiki/ images/e/ed/MPM.pdf, accessed March 21, 2012].

Gloss, S.P., and Coggins, L.G., 2005, Fishes of the Grand Canyon, in Gloss, S.P., Lovich, J.E., and Melis, T.S., eds., The state of the Colorado River ecosystem in Grand Canyon-A report of the Grand Canyon Monitoring and Research Center 1991-2004: U.S. Geological Survey Circular 1282, p. 33-56 [http://pubs.usgs.gov/circ/1282/, accessed May 10, 2010].

Korman, J., and Campana, S.E., 2009, Effects of hydropeaking on nearshore habitat use and growth of age- 0 rainbow trout in a large regulated river: Transactions of the American Fisheries Society, v. 138, no. 1, doi: 10.1577/T08-026.1, p. 76-87 [http://www.tandfonline.com/doi/abs/10.1577/T08026.1, accessed June 1, 2011].

Korman, J., and Melis, T.S., 2011, The effects of Glen Canyon Dam operations on early life stages of rainbow trout in the Colorado River: U.S. Geological Survey Fact Sheet 20113002, 4 p. [http://pubs.usgs.gov/fs/2011/3002/fs2011-3002. pdf, accessed January 19, 2011].
Makinster, A.S., Persons, W.R., and Avery, L.A., 2011, Status and trends of the rainbow trout population in the Lees Ferry Reach of the Colorado River downstream from Glen Canyon Dam, Arizona, 1991-2009: U.S. Geological Survey Scientific Investigations Report 2011-5015, 17 p. [http://pubs.usgs.gov/sir/2011/5015/, accessed June 13, 2011].

Makinster, A.S., Persons, W.R., Avery, L.A., and Bunch, A.J., 2010, Colorado River fish monitoring in Grand Canyon, Arizona-2000 to 2009 summary: U.S. Geological Survey Open-File Report 2010-1246, 26 p. [http://pubs.usgs.gov/ of/2010/1246/, accessed November 5, 2010].

U.S. Bureau of Reclamation, 2011, Environmental assessment-Non-native fish control downstream from Glen Canyon Dam: Salt Lake City, Utah, Bureau of Reclamation, Upper Colorado Region, 102 p. + appendixes [http://www.usbr.gov/uc/envdocs/ea/gc/nnfc/ NNFC-EA.pdf, accessed March 21, 2012].

U.S. Bureau of Reclamation and U.S. Geological Survey Grand Canyon Monitoring and Research Center, 2010, Glen Canyon Dam Adaptive Management Program biennial budget and work plan-fiscal years 2011-12: Salt Lake City, Utah, Bureau of Reclamation, Upper Colorado Regional Office, 250 p. + appendixes.

Waldman, J.R., Dunning, D.J., and Mattson, M.T., 1990, A morphological explanation for size dependent anchor tag loss from striped bass: Transactions of the American Fisheries Society. v. 119, p. 920-923.

Ward, D.L., Persons, W.R., Young, K.L., Stone, D.M., Vanhaverbeke, D.R., and Knight, W.K., in press, A laboratory evaluation of tagging-related mortality and tag loss in juvenile Humpback Chub: North American Journal of Fisheries Management, doi:10.1080/0275594 7.2014 .986345 . 


\section{Appendix A: Field Datasheet Codes}

\begin{tabular}{lll}
\hline & & TURBIDITY CODES \\
\hline $\mathbf{H}$ & & High Secchi $(<0.5 \mathrm{~m})$ \\
$\mathbf{L}$ & & Low Secchi $(>0.5 \mathrm{~m})$ \\
\hline & & \multicolumn{1}{c}{ SUBSTRATE } \\
\hline 0 & SM & Clay-silt-mark $(<0.06 \mathrm{~mm})$ \\
1 & SI & Silt-sand $(0.07-0.10 \mathrm{~mm})$ \\
2 & SA & Sand $(.11-2.0 \mathrm{~mm})$ \\
3 & GR & Gravel $(2.1-15 \mathrm{~mm})$ \\
4 & PB & Pebble $(16-31 \mathrm{~mm})$ \\
5 & RK & Rock $(32-100 \mathrm{~mm})$ \\
6 & CO & Cobble $(101-255 \mathrm{~mm})$ \\
7 & SB & Small boulder $(256-1000 \mathrm{~mm})$ \\
8 & BO & Boulder $(1-3 \mathrm{~m})$ \\
9 & LB & Large boulder $(>3 \mathrm{~m})$ \\
10 & BE & Bedrock \\
11 & OR & Organic matter $/$ detritus
\end{tabular}

\begin{tabular}{|c|c|}
\hline \multicolumn{2}{|r|}{ RIVER CODES } \\
\hline BAC & Bright Angel Creek \\
\hline BAD & Badger Creek \\
\hline BCC & Big Canyon (LCR RKM 11.5) \\
\hline CHU & Chuar Canyon \\
\hline CLR & Clear Creek \\
\hline COR & Colorado River \\
\hline CRY & Crystal Creek \\
\hline DIA & Diamond Creek (RM 225.7) \\
\hline DRC & Deer Creek \\
\hline EMF & Emery Falls Creek (RM 274.3) \\
\hline FAL & Fall Creek (RM -2.5) \\
\hline HAV & Havasu Creek \\
\hline HER & Hermit Creek \\
\hline KAN & Kanab Creek \\
\hline LCR & Little Colorado River \\
\hline LOS & Lost Creek (RM 248.9) \\
\hline MAT & Matkatamiba Creek \\
\hline NAN & Nankoweap Creek \\
\hline PAR & Paria River \\
\hline PHA & Phantom Creek \\
\hline PIP & Pipe Creek \\
\hline QUA & Quartermaster Creek (Rm 259.8) \\
\hline ROY & Royal Arch Creek (Elves Chasm) \\
\hline SAL & Salt Creek (RM 92.5) \\
\hline SHI & Shinumo Creek \\
\hline SHW & Shinumo Wash \\
\hline SPR & Spring Canyon Creek (RM 204.1) \\
\hline STO & Stone Creek \\
\hline TAP & Tapeats Creek \\
\hline TRA & Travertine Creek (RM 230.5) \\
\hline
\end{tabular}

\begin{tabular}{lccc}
\hline & VIE TAG COLOR AND LOCATION CODES & \\
\hline Color & Code & Location & Code \\
Orange & $\mathrm{O}$ & Anal & AN \\
Green & $\mathrm{G}$ & Caudal & CD \\
Red & $\mathrm{R}$ & Dorsal & DR \\
Blue & $\mathrm{B}$ & Front dorsal & FD \\
Pink & $\mathrm{P}$ & Rear dorsal & RD \\
Yellow & $\mathrm{Y}$ & Head & HD \\
Black & $\mathrm{BK}$ & Lip & LP \\
Brown & $\mathrm{BN}$ & Pectoral & P1 \\
Purple & $\mathrm{PU}$ & Pelvic & P2 \\
\hline
\end{tabular}




\begin{tabular}{ll}
\hline & \multicolumn{1}{c}{ FINCLIP CODES } \\
\hline ADP & Adipose \\
ANL & Anal \\
CAU & Caudal \\
DOR & Dorsal \\
LCD & Lower caudal \\
LOP & Left opercle punch \\
LP1 & Left pectoral \\
LP2 & Left pelvic \\
ROP & Right opercle punch \\
RP1 & Right pectoral \\
RP2 & Right pelvic \\
UCD & Upper caudal \\
WA & Wire tag adipose fin \\
WH & Wire tag in head \\
WN & No wire tag detected (fish was checked) \\
\hline
\end{tabular}

\section{SEXUAL CONDITION CODES}

I Immature, sex organs not developed

M Mature, sex organs well developed, eggs distinguishable

N Not Ripe

R Ripe, Gametes extrudable in response to light pressure

S Spent, testes or ovaries empty or red, genital aperture inflamed

U Undetermined

\begin{tabular}{ll}
\hline & \multicolumn{1}{c}{ SEXUAL CHARACTERISTICS CODES } \\
\hline B & Both spawning colors and tuberculated \\
$\mathbf{C}$ & Exhibiting spawning colors \\
$\mathbf{N}$ & None \\
$\mathbf{T}$ & Tuberculated \\
$\mathbf{U}$ & Undetermined \\
\hline
\end{tabular}

\begin{tabular}{ll}
\hline & DISPOSITION CODES \\
\hline RA & Returned alive \\
DR & Dead, released \\
DP & Dead, preserved \\
DS & Dead, stomach contents \\
SK & Dead, skeletonized \\
\hline
\end{tabular}

\section{PARASITE CODES}

\begin{tabular}{ll}
\hline $\mathbf{L}$ & Lernaea \\
$\mathbf{B}$ & Asian tapeworm \\
$\mathbf{B L}$ & Asian tapeworm \& Lernaea \\
$\mathbf{U}$ & Unidentified \\
$\mathbf{N}$ & None \\
\hline
\end{tabular}

\section{SPECIES CODES}

\begin{tabular}{ll}
\hline BBH & Black bullhead \\
BGS & Bluegill sunfish \\
BHS & Bluehead sucker \\
BKC & Black crappie \\
BKT & Brook trout \\
BNT & Brown trout \\
CCF & Channel catfish \\
CRP & Carp \\
CUT & Cutthroat trout \\
FHM & Fathead minnow \\
FMS & Flannelmouth sucker \\
FRH & Flannelmouth/razorback hybrid \\
GAM & Gambusia \\
GSF & Green sunfish \\
GSH & Golden shiner \\
GZD & Gizzard shad \\
HBC & Humpback chub \\
LMB & Largemouth bass \\
NOP & Northern pike \\
PKF & Plains killifish \\
RBS & Razorback sucker \\
RBT & Rainbow trout \\
STB & Striped bass \\
SUC & Unidentified sucker \\
TFS & Threadfin shad \\
UID & Unidentified fish \\
UTC & Utah chub \\
WAL & Walleye \\
YBH & Yellow bullhead \\
\hline &
\end{tabular}

Menlo Park Publishing Service Center

Manuscript approved for publication December 3, 2012 Edited by George Havach and Claire Landowski Layout and design by Jeanne S. DiLeo 
